\title{
Clinical Outcomes of Percutaneous Coronary Intervention in Patients Turned Down for Surgical Revascularization
}

\author{
Running Title: PCl Outcomes in Patients Turned Down for Surgery
}

Devraj Sukul, MD푸 ${ }^{1}$ Milan Seth, $\mathrm{MS}^{1}$; Simon R. Dixon, $\mathrm{MBChB}^{2}$; Mark Zainea, $\mathrm{MD}^{3}$; Nicklaus K. Slocum, MD ; Elizabeth J. Pielsticker, MD ${ }^{5}$; Hitinder S. Gurm, MD ${ }^{1,6}$

${ }^{1}$ Department of Internal Medicine, Division of Cardiovascular Medicine, University of Michigan, Ann Arbor, Michigan, ${ }^{2}$ William Beaumont Hospital, Heart and Vascular, Royal Oak, MI, ${ }^{3}$ McLaren Macomb Hospital, Roseville, MI, ${ }^{4}$ Traverse Heart \& Vascular, Traverse City, MI, ${ }^{5}$ St Joseph Mercy Health System, Michigan Heart, Jackson, MI, ${ }^{6}$ Veterans Affairs Medical Center, Ann Arbor, MI

\section{Support:}

Support for BMC2 is provided by Blue Cross and Blue Shield of Michigan and Blue Care Network as part of the BCBSM Value Partnerships program.

Disclaimer: Although Blue Cross Blue Shield of Michigan and BMC2 work collaboratively, the opinions, beliefs and viewpoints expressed by the author do not necessarily reflect the opinions, beliefs and viewpoints of BCBSM or any of its employees.

\section{Conflict of Interest/Disclosures:}

Hitinder S. Gurm receives research funding from Blue Cross Blue Shield of Michigan, the National Institutes of Health and is a consultant for Osprey Medical. None of the authors have any conflicts directly relevant to this study.

\section{Corresponding Author:}

Hitinder S. Gurm, MD

2A 394, 1500 East Medical Ctr Drive, University of Michigan Cardiovascular Center Ann Arbor, MI 48109-5853

hgurm@med.umich.edu

Word Count: 4255

This is the author manuscript accepted for publication and has undergone full peer review but has not been through the copyediting, typesetting, pagination and proofreading process, which may lead to differences between this version and the Version record. Please cite this article as doi:10.1002/ ccd.26781. 


\section{STRUCTURED ABSTRACT:}

OBJECTIVES: We examined clinical outcomes following percutaneous coronary intervention $(\mathrm{PCl})$ in patients turned down for surgical revascularization across a broad population.

BACKGROUND: Prior studies suggest that surgical ineligibility is associated with increased mortality in patients with unprotected left main or multivessel coronary artery disease undergoing $\mathrm{PCl}$.

METHODS: This study included consecutive patients who underwent $\mathrm{PCl}$ in a multicenter registry in Michigan from 1/2010 - 12/2014. Surgical ineligibility required documentation indicating that a cardiac surgeon deemed the patient ineligible for surgery. In-hospital outcomes included mortality (primary outcome), cardiogenic shock, cerebrovascular accident, contrastinduced nephropathy (CIN), and a new requirement for dialysis (NRD).

RESULTS: Of 99,370 patients at 33 hospitals with on-site surgical backup, 1,922 (1.9\%) were surgically ineligible. The rate of ineligibility did not vary by hospital (range: $1.5 \%-2.5 \% ; p=0.79$ ).

Overall, there were no major differences in baseline characteristics or outcomes between surgically ineligible patients and the rest (i.e. non-ineligible patients): mortality $(0.52 \%$ vs.

$0.52 \% ; p>0.5)$, cardiogenic shock $(0.68 \%$ vs. $0.73 \% ; p>0.5)$, cerebrovascular accident $(0.05 \%$ vs. $0.19 \% ; p=0.28), \operatorname{NRD}(0.16 \%$ vs. $0.19 \% ; p>0.5)$, CIN (2.7\% vs. $2.3 \% ; p=0.27)$. Among 1,074 patients who underwent unprotected left main $\mathrm{PCl}, 20$ (1.9\%) were surgically ineligible and experienced increased rates of mortality ( $20.0 \%$ vs. $5.3 \% ; p=0.022 ;$ adjusted $O R=7.38 ; p<0.001)$ and other complications as compared to the remainder.

CONCLUSIONS: $\mathrm{PCI}$ in a broad population of surgically ineligible patients is generally safe. However, among patients who underwent unprotected left main $\mathrm{PCl}$, those deemed surgically ineligible experienced significantly worse outcomes as compared to the rest. 
KEY WORDS: percutaneous coronary intervention (PCI); coronary artery bypass grafting; health care outcomes; risk stratification; coronary artery disease ABSTRACT WORD COUNT: 247 (limit 250)

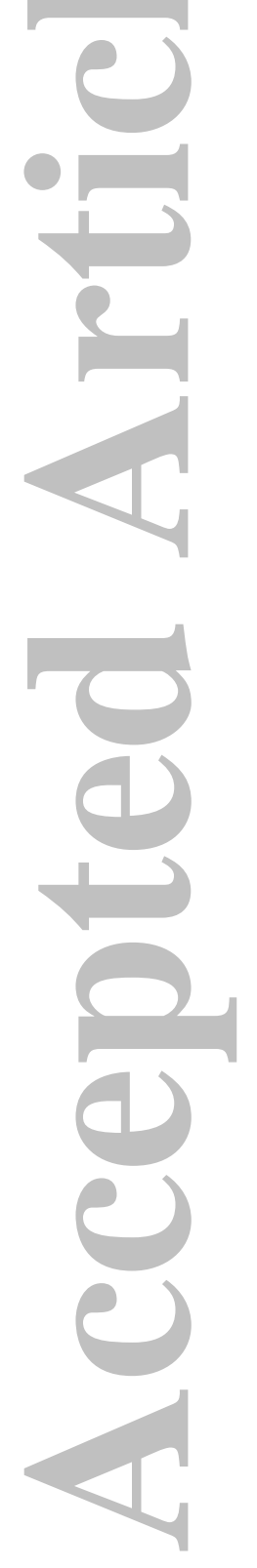

Catheterization and Cardiovascular Interventions

This article is protected by copyright. All rights reserved. 
CONDENSED ABSTRACT: Using a large, multicenter, regional registry of $\mathrm{PCl}$, this study examined the relationship between surgical ineligibility and clinical outcomes after $\mathrm{PCl}$. In the overall study cohort $(n=99,370), \mathrm{PCl}$ appears to be safe in surgically ineligible patients as there was no significant difference in outcomes between ineligible patients as compared to the rest. Importantly, surgical ineligibility was associated with worse outcomes in patients undergoing unprotected left main $\mathrm{PCl}$.
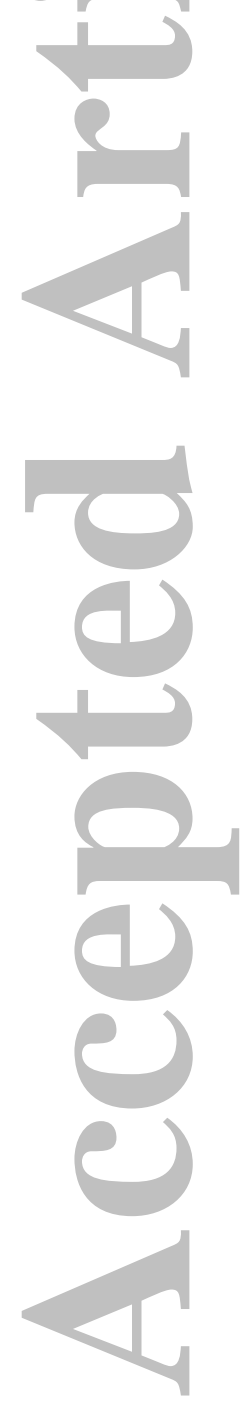


\section{ABBREVIATIONS \& ACRONYMS:}

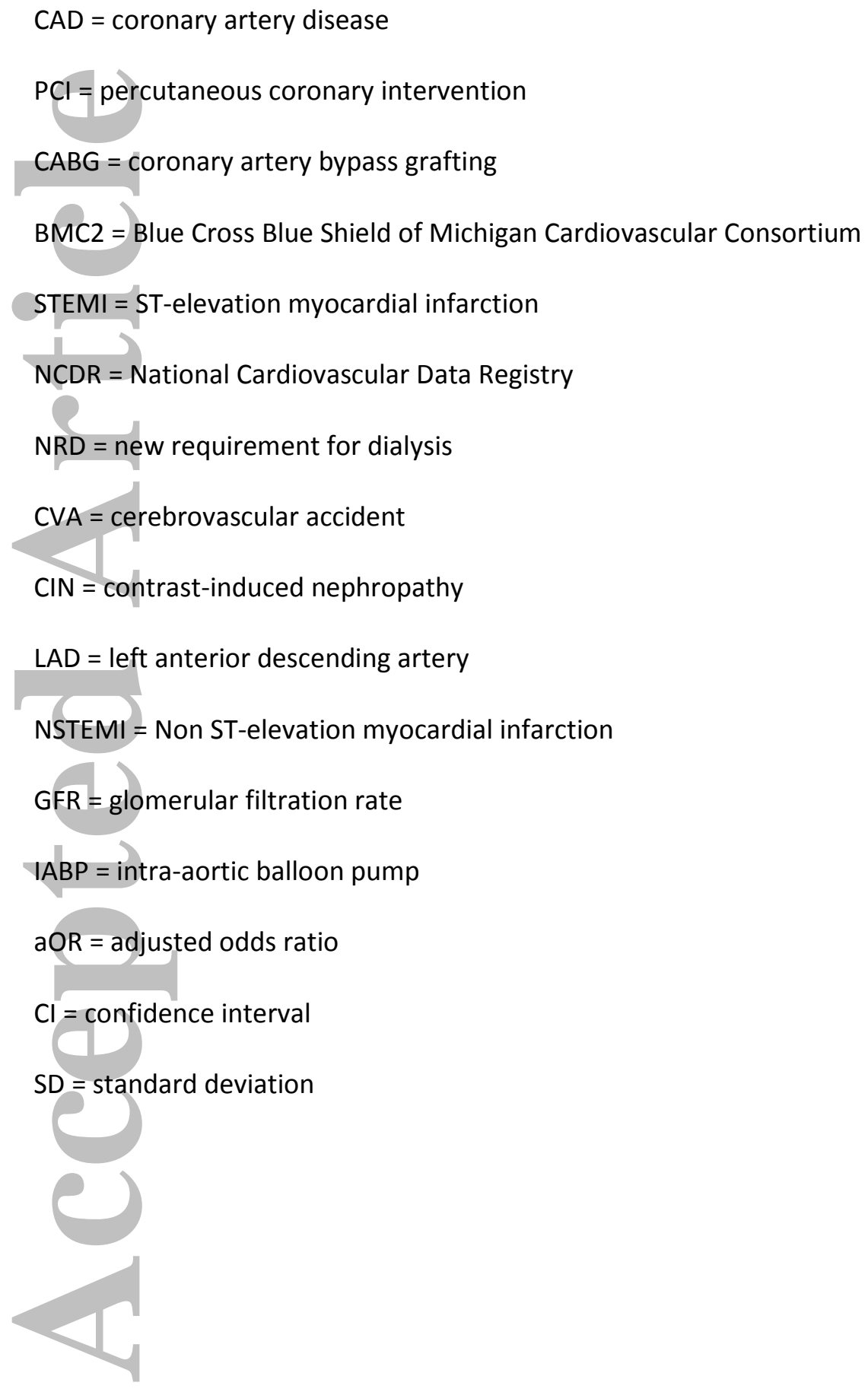




\section{INTRODUCTION}

The optimal method of revascularization for coronary artery disease (CAD), whether it is percutaneous coronary intervention ( $\mathrm{PCl}$ ) or coronary artery bypass grafting (CABG), has been a controversial and frequent topic of research for many years (1-12). Physicians consider numerous factors when formulating their recommendation for revascularization, including, but not limited to, the presence of diabetes mellitus, chronic kidney disease, systolic dysfunction, prior CABG, and the complexity of CAD (13-15). In recent years, clinical guidelines and appropriate use criteria have been developed to assist physicians in making evidence-based recommendations $(13,14,16)$.

Nevertheless, the decision to recommend surgical or percutaneous revascularization is complex, frequently requiring the input of general cardiologists, interventional cardiologists, and cardiac surgeons. Clinical guidelines advocate for a team-based, multidisciplinary, "Heart Team" approach to determining the optimal revascularization strategy for complex patients $(13,14,16)$. Through this multidisciplinary approach, patients may be deemed ineligible for a particular revascularization option.

Recent research has demonstrated that patients with unprotected left main or multivessel CAD who are deemed ineligible for surgical revascularization experience worse outcomes after $\mathrm{PCl}$ as compared to patients not deemed ineligible $(17,18)$. These studies reflect the experiences of $\mathrm{PCl}$ at tertiary care institutions. Historically, surgically ineligible patients referred for $\mathrm{PCl}$ are thought to represent a high-risk cohort. The characteristics and outcomes of $\mathrm{PCl}$ in patients turned down for surgical revascularization in broad community practice have not been studied. Therefore, using a large regional PCl database, we sought to describe the characteristics and outcomes of $\mathrm{PCl}$ in patients with documented surgical ineligibility within a diverse array of $\mathrm{PCl}$-capable hospitals. 


\section{METHODS}

We performed a retrospective analysis on data from the Blue Cross Blue Shield of Michigan Cardiovascular Consortium (BMC2), a regional registry of all patients undergoing $\mathrm{PCl}$ in Michigan. A more complete description of the registry, including data collection and auditing practices, has been described previously $(19,20)$. Briefly, this is a prospective, multicenter, statewide registry of patients undergoing $\mathrm{PCl}$ at any of the non-federal hospitals in Michigan. For the current study, consecutive patients undergoing PCI between January 2010 and December 2014 at the 33 hospitals with on-site cardiac surgery were included.

Patients that presented with ST-elevation myocardial infarction (STEMI) or preprocedural cardiac arrest were excluded due to the emergent nature of treatment and a bias towards $\mathrm{PCl}$ in these individuals. Patients with a history of CABG were excluded, as the decision to recommend surgical or percutaneous revascularization often hinges on unique and important considerations such as repeat sternotomy, graft anatomy, and conduit availability. Finally, patients that underwent salvage $\mathrm{PCl}$ were excluded given the use of $\mathrm{PCl}$ as a last resort in these critically ill patients. Salvage $\mathrm{PCl}$ was defined as $\mathrm{PCl}$ in a patient who, within ten minutes prior to the start of the procedure, has received chest compressions or has been on unanticipated extracorporeal circulatory support (21). Surgical ineligibility was defined as written documentation indicating that the patient was evaluated by a cardiac surgeon and felt not to be a surgical candidate for any reason. We did not collect information regarding the reason for surgical referral or for surgical ineligibility, as these reasons are often heterogeneous and poorly defined. We divided patients into two groups, those turned down for surgical revascularization and the remainder (who may or may not have been evaluated by a cardiac surgeon).

Outcomes and Subgroup Analysis 
All outcomes were measured during the incident hospitalization when $\mathrm{PCl}$ was

performed. The primary outcome measure was in-hospital mortality attributable to any cause.

Secondary outcomes included the development of post-procedure cardiogenic shock,

cerebrovascular accident (CVA), contrast-induced nephropathy (CIN), and a new requirement for dialysis (NRD). Post-procedure cardiogenic shock and CVA were defined as per the NCDR

CathPCI registry definition (21). CIN was defined as renal dysfunction resulting in a $0.5 \mathrm{mg} / \mathrm{dL}$

absolute increase in a post-procedure creatinine measurement as compared to baseline. NRD

was defined as any new, unplanned need for dialysis after PCI.

Clinical outcomes are reported for the overall cohort and by subgroups defined by percutaneously treated CAD anatomy. Diagnostic catheterization data were not routinely collected on all patients in the registry; therefore, we defined CAD anatomy by the site(s) of PCI per catheterization lab visit. Complex disease was defined as unprotected left main $\mathrm{PCl}$, threevessel $\mathrm{PCl}$, or two-vessel with proximal left anterior descending (LAD) PCI. Due to the exclusion of patients with prior $C A B G$, all left main PCls were considered unprotected. The hierarchy of categorization also followed the aforementioned sequence. For example, a patient who underwent left main and proximal LAD PCI would be classified as having left main disease, not two-vessel with proximal LAD disease. All other patients were categorized as having noncomplex disease.

\section{Statistical Analysis}

Baseline characteristics and outcomes were compared between surgically ineligible patients and the remainder using Pearson $\chi 2$ or Fisher's exact test for categorical variables and Student t-tests for continuous variables. Continuous variables were summarized using mean \pm SD. Outcome rates by surgical ineligibility were compared using Fisher's exact test. Pre- 
procedural risks of mortality, $\mathrm{CIN}$, and need for transfusion were estimated using the BMC2 random forest prediction models (available for review at https://bmc2.org/calculators/multi). The methodology and specific implementations for CIN and transfusion endpoints have been validated and previously described elsewhere $(22,23)$.

For the primary outcome of mortality, hierarchical logistic regression models were utilized incorporating patient baseline mortality risk and PCI-treated CAD anatomy as fixed effects and

effects and accounting for potential hospital level variability through the inclusion of a hospital random intercept. All analyses were performed using R version 3.2.1 (24). Hierarchical generalized mixed effects regression models were fitted using the Ime4 R package (25).

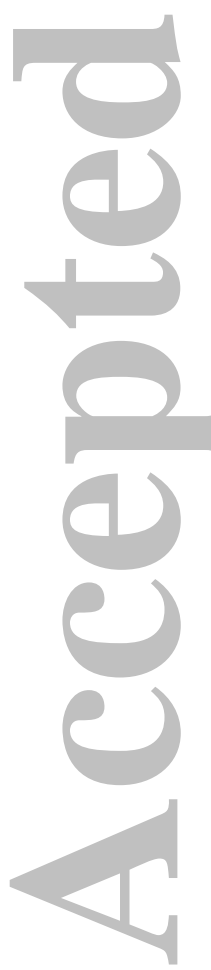




\section{RESULTS}

A total of 151,223 patients underwent $\mathrm{PCl}$ at the 33 participating centers between January 2010 and December 2014. Of these, 24,153 (16.0\%) presented with STEMI, 2,893 (1.9\%) experienced a pre-procedure cardiac arrest, $283(0.2 \%)$ underwent salvage $\mathrm{PCl}$, and 28,242 (18.7\%) had a history of CABG. A total of 51,853 (34.3\%) patients met at least one exclusion criteria, leaving 99,370 patients in the overall cohort. A total of 1,922 (1.9\%) patients were turned down for surgery. The baseline characteristics of surgically ineligible patients and the remainder are presented in Table 1 . The two groups were largely similar in their baseline characteristics, with only prior myocardial infarction and prior $\mathrm{PCl}$ having occurred at a greater frequency in patients ineligible for surgery.

There was no significant site-level variation in the incidence of surgically ineligible patients across the 33 hospitals with on-site surgical backup (range: $1.5 \%$ to $2.5 \% ; X^{2}=25.5$ on $32 \mathrm{df} ; \mathrm{p}>0.5$ ) (Figure 1). In-hospital mortality was similar between the two groups $(0.52 \%$ vs. (1)

$0.52 \% ; p>0.5$; Figure 2), and no significant difference was observed after adjusting for preprocedural predicted risk of mortality, $\mathrm{PCl}$-treated CAD anatomy, and hospital-level clustering in a hierarchical regression model (adjusted odds ratio $[\mathrm{aOR}]=1.11 ; 95 \%$ confidence interval $[\mathrm{Cl}]$ $0.57-2.15 ; p>0.5)$. Furthermore, no significant differences were noted in secondary outcome measures (Figure 2).

Stratification by PCI-treated CAD anatomy A total of 4,438 patients were defined as having complex disease, of which 81 patients (1.8\%) had documentation of surgical ineligibility. The majority $(95.8 \% ; n / N=1,841 / 1,922)$ of surgically ineligible patients had non-complex disease (Table 2). There was no difference in the distribution of $\mathrm{PCl}$-treated $\mathrm{CAD}$ anatomy between patients turned down and not turned down 
for surgery $(p>0.5)$. Of note, no surgically ineligible patients underwent three-vessel PCI. No significant differences in primary or secondary outcomes were observed in any PCI-treated CAD anatomy subgroup other than left main $\mathrm{PCl}$ patients.

Among patients who underwent left main $\mathrm{PCI}(\mathrm{n}=1,074)$, those deemed surgically ineligible $(n=20)$ had significantly increased rates of in-hospital mortality $(20.0 \%$ vs. $5.3 \% ; p=$ $0.022)$, cardiogenic shock ( $25.0 \%$ vs. $5.1 \% ; p=0.004)$, and NRD $(10.5 \%$ vs. $1.6 \% ; p=0.042)$ as compared to the remainder ( $n=1,054$; Figure 3). Of note, $40 \%(n / N=4 / 10)$ of in-hospital deaths in all surgically ineligible patients occurred in those who underwent left main PCI.

The effect of surgical ineligibility on mortality varied significantly between patients with left main PCI compared to those with other PCI-treated CAD anatomy after adjusting for predicted pre-procedural mortality risk, CAD anatomy, and hospital-level clustering (Likelihood ratio test for left main $\mathrm{PCl}$ by ineligibility interaction: $\mathrm{LRT}=12.7$ on $1 \mathrm{df}, \mathrm{p}<0.0001$ ). In stratified, adjusted hierarchical regression analysis, again adjusting for predicted baseline risk and hospital level clustering fit within the left main $\mathrm{PCl}$ subgroup, mortality was strongly associated with surgical ineligibility $(\mathrm{aOR}=7.38,95 \% \mathrm{Cl} 2.32-23.49, \mathrm{p}<0.001)$. 


\section{DISCUSSION}

Recent research has demonstrated that surgical ineligibility is associated with inferior outcomes after $\mathrm{PCl}$ in patients with complex $\operatorname{CAD}(17,18)$. Our study significantly adds to this body of literature through three major findings. First, it appears that broadly, $\mathrm{PCl}$ in patients deemed ineligible for surgical revascularization is safe, given that there is no significant difference in multiple, clinically relevant, in-hospital outcomes including death. Second, as noted in prior studies, individuals who were deemed ineligible for surgery and underwent left main PCI suffered significantly worse outcomes as compared to the rest of the cohort, highlighting the potential additive effect of surgical ineligibility in high-risk, complex $\operatorname{CAD}(17,18)$. Third, there was no significant variation in the frequency of $\mathrm{PCl}$ in surgically ineligible patients amongst a diverse group of $\mathrm{PCl}$-capable hospitals within this region.

Though $\mathrm{PCl}$ in patients with documented surgical ineligibility appears to be safe, these findings must be interpreted with certain caveats. One potential reason why $\mathrm{PCl}$ appears safe in this population may be because these surgically ineligible patients were inherently deemed eligible for $\mathrm{PCl}$ by the interventional cardiologist performing the procedure. Undoubtedly, there are patients who are deemed ineligible for surgery and $\mathrm{PCl}$, thereby never undergoing revascularization. The outcomes of these patients were not collected or reported.

When assessing the outcomes of $\mathrm{PCl}$ by $\mathrm{PCl}$-treated $\mathrm{CAD}$ anatomy, we attempted to classify patients according to the severity of their disease by using the appropriate use criteria for multivessel disease as a guide (16). Patients who underwent two-vessel with proximal LAD $\mathrm{PCl}$ experienced similar outcomes when stratified by surgical ineligibility. There is a possibility that this finding is due to misclassification of CAD complexity, given that we classified CAD anatomy based on lesions treated by $\mathrm{PCl}$ and not native $\mathrm{CAD}$ at the time of diagnostic 
catheterization. Therefore, patients with multivessel complex CAD who underwent staged PCI may have been categorized as having non-complex disease. Additionally, some patients with multivessel native CAD would have been categorized as having non-complex disease if they underwent $\mathrm{PCl}$ of select lesions (i.e. incomplete revascularization), if the interventional cardiologist felt that this would provide the optimal risk/benefit ratio. Nevertheless, the generally favorable outcomes in the overall population are reassuring.

Though only 20 surgically ineligible patients underwent left main PCI, 4 (20\%) died during the hospitalization. This surgically ineligible subgroup also had increased rates of cardiogenic shock and NRD. Even after adjustment, surgical ineligibility was associated with a 7fold increase in in-hospital mortality in this subgroup. Although the absolute number of patients in this subgroup is small, this finding is consistent with prior studies assessing the relationship between surgical ineligibility and $\mathrm{PCl}$ outcomes $(17,18)$. Future studies should attempt to elucidate the specific, and often complex, reasons for surgical ineligibility that may confer this increased risk. It is also noteworthy that a substantially larger number of patients underwent left main $\mathrm{PCl}$ without being turned down for surgery and the general outcome in this cohort was excellent. Although the total number of patients who were referred to surgery for left main disease is not available, it is likely that these 20 patients represent a highly selected and unique subset of patients who were at a high risk of adverse outcomes from either revascularization strategy.

Multiple studies have demonstrated significant hospital-level variation for a number of important cardiovascular outcomes (26-28). The 33 nonfederal PCl-capable hospitals in our statewide registry vary from community hospitals to quaternary teaching hospitals. We found no significant difference in the rate of $\mathrm{PCl}$ in surgically ineligible patients across these hospitals. This suggests that practice patterns are broadly similar across the state. Notably, both 
interventional cardiologists and cardiac surgeons participate in statewide collaborative quality improvement initiatives and such practice uniformity may or may not exist across geographic regions that do not participate in such initiatives (29).

Clinical guidelines advocate for the use of a multidisciplinary Heart Team approach when evaluating revascularization options for patients with complex CAD $(13,14,16)$. Therefore, it is surprising that the vast majority of surgically ineligible patients $(95.8 \%)$ had non-complex disease. As stated above, this number may be an overestimate due to our classification scheme. Nevertheless, even if we were to assume a substantial proportion of misclassification, the majority of patients would still likely have non-complex disease. It is unclear why these patients were referred for surgery, let alone deemed ineligible. It is possible that these patients may have had more diffuse and complex coronary lesions or other cardiac conditions such as severe valve disease that may have led to surgical referral. In the future, the number of patients with complex CAD evaluated for surgical and percutaneous revascularization options will likely increase as the utilization of a Heart Team approach grows (30-32). We suspect that documentation of these collaborative decisions will provide a better understanding of referral practices between cardiologists and cardiac surgeons and allow for more rigorous research into the effects of surgical ineligibility on patient outcomes.

Fortunately, through the emergence of new healthcare information technologies and the mandate for the meaningful use of electronic health records, "big data" analytics may be able to help us better understand these issues in the future. For example, the application of natural language processing systems to electronic medical records have already resulted in improved prediction and detection of outcomes, and is being used to develop clinical registries (33-35). We imagine that the application of these technologies to the vast wealth of clinical information in electronic health records will ultimately allow us to obtain a more complete and

\section{Catheterization and Cardiovascular Interventions}

This article is protected by copyright. All rights reserved. 
nuanced understanding of complex clinical decisions such as the reasons for surgical referral and the rationale for surgical ineligibility (or eligibility) in patients with CAD.

There are several limitations in our study that deserve specific mention. First, as noted above, we may have potentially misclassified the complexity of CAD due to inherent limitations in the accurate collection of native CAD anatomy, requiring us to use percutaneously treated CAD anatomy. Second, the registry follows a rigorous definition for surgical ineligibility, and surgical ineligibility cannot be assigned by a cardiologist or following a "curbside" consult. We had no method of accounting for non-documented surgical ineligibility, but our rigorous definition would increase the specificity of our findings. Furthermore, as noted by Gasparovic et al, we believe that in order to accurately study the association between surgical ineligibility and $\mathrm{PCl}$ outcomes, cardiac surgeons, not surrogate decision-makers, should determine a patient's eligibility for surgery (36). Third, we do not have data on intermediate- and long-term outcomes. As demonstrated previously, there may be a more substantial difference in outcomes between these two groups in the long-term $(17,18)$. Fourth, despite collecting PCl information from multiple centers over a 4-year time period, our statistical power to detect significant differences in outcomes was limited by the small number of patients deemed surgically ineligible. This limitation underscores the need for ongoing research studying the impact of surgical ineligibility on $\mathrm{PCl}$ outcomes, and the consideration of including this variable in large, national $\mathrm{PCl}$ registries.

\section{CONCLUSIONS}

$\mathrm{PCl}$ in a broad population of surgically ineligible patients appears safe, potentially highlighting the discretion utilized by interventional cardiologists in selecting these patients. Importantly though, there is a substantial effect of surgical ineligibility on mortality in the subgroup of patients who underwent unprotected left main $\mathrm{PCl}$, although this finding should be 
interpreted with caution as only 20 surgically ineligible patients underwent left main PCl. Our findings may assist physicians and patients in more accurately estimating the risks associated with $\mathrm{PCl}$ in patients with documented surgical ineligibility.

\section{ACKNOWLEDGEMENTS:}

The authors are indebted to all the study coordinators, investigators, and patients who participated in the Blue Cross Blue Shield of Michigan Cardiovascular Consortium registry.
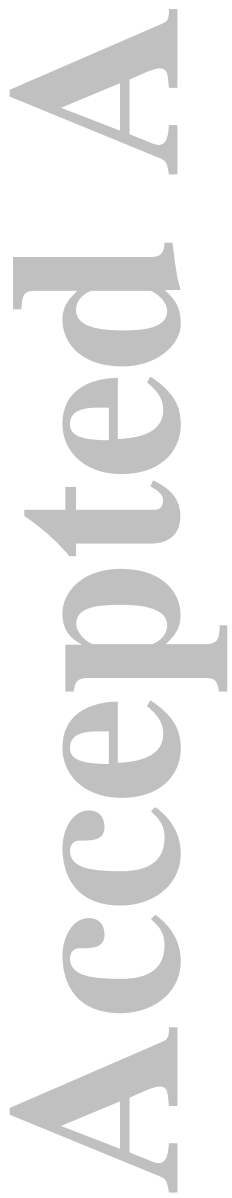

Catheterization and Cardiovascular Interventions

This article is protected by copyright. All rights reserved. 


\section{REFERENCES}

1. Al Ali J, Franck C, Filion KB, Eisenberg MJ. Coronary artery bypass graft surgery versus percutaneous coronary intervention with first-generation drug-eluting stents: a metaanalysis of randomized controlled trials. JACC Cardiovasc Interv 2014;7:497-506.

2. Comparison of coronary bypass surgery with angioplasty in patients with multivessel disease. The Bypass Angioplasty Revascularization Investigation (BARI) Investigators. N Engl J Med 1996;335:217-25.

3. Chieffo A, Magni V, Latib A, Maisano F, lelasi A, Montorfano M, Carlino M, Godino C, Ferraro M, Calori G and others. 5-year outcomes following percutaneous coronary intervention with drug-eluting stent implantation versus coronary artery bypass graft for unprotected left main coronary artery lesions the Milan experience. JACC Cardiovasc Interv 2010;3:595-601.

4. Deb S, Wijeysundera HC, Ko DT, Tsubota H, Hill S, Fremes SE. Coronary artery bypass graft surgery vs percutaneous interventions in coronary revascularization: a systematic review. JAMA 2013;310:2086-95.

5. Fukui T, Tabata M, Tobaru T, Asano R, Takanashi S, Sumiyoshi T. Early and long-term outcomes of coronary artery bypass grafting and percutaneous coronary intervention in patients with left main disease: single-center results of multidisciplinary decision making. Gen Thorac Cardiovasc Surg 2014;62:301-7.

6. Hamm CW, Reimers J, Ischinger T, Rupprecht HJ, Berger J, Bleifeld W. A randomized study of coronary angioplasty compared with bypass surgery in patients with symptomatic multivessel coronary disease. German Angioplasty Bypass Surgery Investigation (GABI). N Engl J Med 1994;331:1037-43. 
7. Hannan EL, Zhong Y, Walford G, Holmes DR, Jr., Venditti FJ, Berger PB, Jacobs AK, Stamato NJ, Curtis JP, Sharma S and others. Coronary artery bypass graft surgery versus drug-eluting stents for patients with isolated proximal left anterior descending disease. J Am Coll Cardiol 2014;64:2717-26.

8. Hlatky MA, Boothroyd DB. Comparative effectiveness of multivessel coronary artery bypass graft surgery and multivessel percutaneous coronary intervention. Ann Intern Med 2013;159:435.

9. Naik H, White AJ, Chakravarty T, Forrester J, Fontana G, Kar S, Shah PK, Weiss RE, Makkar R. A meta-analysis of 3,773 patients treated with percutaneous coronary intervention or surgery for unprotected left main coronary artery stenosis. JACC Cardiovasc Interv 2009;2:739-47.

10. Park DW, Kim YH, Yun SC, Lee JY, Kim WJ, Kang SJ, Lee SW, Lee CW, Kim JJ, Choo SJ and others. Long-term outcomes after stenting versus coronary artery bypass grafting for unprotected left main coronary artery disease: 10 -year results of bare-metal stents and 5-year results of drug-eluting stents from the ASAN-MAIN (ASAN Medical Center-Left MAIN Revascularization) Registry. J Am Coll Cardiol 2010;56:1366-75.

11. Serruys PW, Morice MC, Kappetein AP, Colombo A, Holmes DR, Mack MJ, Stahle E, Feldman TE, van den Brand M, Bass EJ and others. Percutaneous coronary intervention versus coronary-artery bypass grafting for severe coronary artery disease. $\mathrm{N}$ Engl J Med 2009;360:961-72.

12. Sipahi I, Akay MH, Dagdelen S, Blitz A, Alhan C. Coronary artery bypass grafting vs percutaneous coronary intervention and long-term mortality and morbidity in multivessel disease: meta-analysis of randomized clinical trials of the arterial grafting and stenting era. JAMA Intern Med 2014;174:223-30. 
13. Hillis LD, Smith PK, Anderson JL, Bittl JA, Bridges CR, Byrne JG, Cigarroa JE, Disesa VJ, Hiratzka LF, Hutter AM, Jr. and others. 2011 ACCF/AHA Guideline for Coronary Artery Bypass Graft Surgery: executive summary: a report of the American College of Cardiology Foundation/American Heart Association Task Force on Practice Guidelines. Circulation 2011;124:2610-42.

14. Levine GN, Bates ER, Blankenship JC, Bailey SR, Bittl JA, Cercek B, Chambers CE, Ellis SG, Guyton RA, Hollenberg SM and others. 2011 ACCF/AHA/SCAI Guideline for Percutaneous Coronary Intervention: a report of the American College of Cardiology Foundation/American Heart Association Task Force on Practice Guidelines and the Society for Cardiovascular Angiography and Interventions. Circulation 2011;124:e574651.

15. (1)

Mohr FW, Morice MC, Kappetein AP, Feldman TE, Stahle E, Colombo A, Mack MJ, Holmes DR, Jr., Morel MA, Van Dyck N and others. Coronary artery bypass graft surgery versus percutaneous coronary intervention in patients with three-vessel disease and left main coronary disease: 5-year follow-up of the randomised, clinical SYNTAX trial. Lancet 2013;381:629-38.

16. Patel MR, Dehmer GJ, Hirshfeld JW, Smith PK, Spertus JA. ACCF/SCAI/STS/AATS/AHA/ASNC/HFSA/SCCT 2012 Appropriate use criteria for coronary revascularization focused update: a report of the American College of Cardiology Foundation Appropriate Use Criteria Task Force, Society for Cardiovascular Angiography and Interventions, Society of Thoracic Surgeons, American Association for Thoracic Surgery, American Heart Association, American Society of Nuclear Cardiology, and the Society of Cardiovascular Computed Tomography. J Am Coll Cardiol 2012;59:857-81. 
17. McNulty EJ, Ng W, Spertus JA, Zaroff JG, Yeh RW, Ren XM, Lundstrom RJ. Surgical candidacy and selection biases in nonemergent left main stenting: implications for observational studies. JACC Cardiovasc Interv 2011;4:1020-7.

18. Waldo SW, Secemsky EA, O'Brien C, Kennedy KF, Pomerantsev E, Sundt TM, 3rd, McNulty EJ, Scirica BM, Yeh RW. Surgical ineligibility and mortality among patients with unprotected left main or multivessel coronary artery disease undergoing percutaneous coronary intervention. Circulation 2014;130:2295-301.

19. Kline-Rogers E, Share D, Bondie D, Rogers B, Karavite D, Kanten S, Wren P, Bodurka C, Fisk C, McGinnity J and others. Development of a multicenter interventional cardiology database: the Blue Cross Blue Shield of Michigan Cardiovascular Consortium (BMC2) experience. J Interv Cardiol 2002;15:387-92.

20. Moscucci M, Rogers EK, Montoye C, Smith DE, Share D, O'Donnell M, Maxwell-Eward A, Meengs WL, De Franco AC, Patel K and others. Association of a continuous quality improvement initiative with practice and outcome variations of contemporary percutaneous coronary interventions. Circulation 2006;113:814-22.

21. NCDR CathPCI Registry v4.4 Coder's Data Dictionary. https://www.ncdr.com/WebNCDR/docs/public-data-collectiondocuments/cathpci v4 codersdictionary 4-4.pdf?sfvrsn=2. Accessed 28 July, 2015.

22. Gurm HS, Kooiman J, LaLonde T, Grines C, Share D, Seth M. A random forest based risk model for reliable and accurate prediction of receipt of transfusion in patients undergoing percutaneous coronary intervention. PLoS One 2014;9:e96385.

23. Gurm HS, Seth M, Kooiman J, Share D. A novel tool for reliable and accurate prediction of renal complications in patients undergoing percutaneous coronary intervention. J Am Coll Cardiol 2013;61:2242-8. 
24. R Development Core Team. R: A language and environment for statistical computing. Vienna, Austria: R Foundation for Statistical Computing; 2015.

25. Bates D, Maechler M, Bolker B, Walker S. Ime4: Linear mixed-effects models using Eigen and S4. R Package version 1.1-7; 2014.

26. Chan PS, Nichol G, Krumholz HM, Spertus JA, Nallamothu BK, American Heart Association National Registry of Cardiopulmonary Resuscitation I. Hospital variation in time to defibrillation after in-hospital cardiac arrest. Arch Intern Med 2009;169:1265-73.

27. Panaich SS, Badheka AO, Arora S, Patel NJ, Thakkar B, Patel N, Singh V, Chothani A, Deshmukh A, Agnihotri K and others. Variability in utilization of drug eluting stents in United States: Insights from nationwide inpatient sample. Catheter Cardiovasc Interv 2015.

28. Yeh RW, Rosenfield K, Zelevinsky K, Mauri L, Sakhuja R, Shivapour DM, Lovett A, Weiner BH, Jacobs AK, Normand SL. Sources of hospital variation in short-term readmission rates after percutaneous coronary intervention. Circ Cardiovasc Interv 2012;5:227-36.

29. Share DA, Campbell DA, Birkmeyer N, Prager RL, Gurm HS, Moscucci M, Udow-Phillips M, Birkmeyer JD. How a regional collaborative of hospitals and physicians in Michigan cut costs and improved the quality of care. Health Aff (Millwood) 2011;30:636-45.

30. Chu D, Anastacio MM, Mulukutla SR, Lee JS, Smith AJ, Marroquin OC, Sanchez CE, Morell VO, Cook CC, Lico SC and others. Safety and efficacy of implementing a multidisciplinary heart team approach for revascularization in patients with complex coronary artery disease: an observational cohort pilot study. JAMA Surg 2014;149:1109-12.

31. Long J, Luckraz H, Thekkudan J, Maher A, Norell M. Heart team discussion in managing patients with coronary artery disease: outcome and reproducibility. Interact Cardiovasc Thorac Surg 2012;14:594-8. 
32. Passeri JJ, Melnitchouk S, Palacios IF, Sundt TM. Continued expansion of the Heart Team concept. Future Cardiol 2015;11:219-28.

33. Al-Haddad MA, Friedlin J, Kesterson J, Waters JA, Aguilar-Saavedra JR, Schmidt CM. Natural language processing for the development of a clinical registry: a validation study in intraductal papillary mucinous neoplasms. HPB (Oxford) 2010;12:688-95.

34. Murff HJ, FitzHenry F, Matheny ME, Gentry N, Kotter KL, Crimin K, Dittus RS, Rosen AK, Elkin PL, Brown SH and others. Automated identification of postoperative complications within an electronic medical record using natural language processing. JAMA 2011;306:848-55.

35. Wasfy JH, Singal G, O'Brien C, Blumenthal DM, Kennedy KF, Strom JB, Spertus JA, Mauri

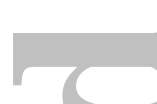
L, Normand SL, Yeh RW. Enhancing the Prediction of 30-Day Readmission After Percutaneous Coronary Intervention Using Data Extracted by Querying of the Electronic Health Record. Circ Cardiovasc Qual Outcomes 2015;8:477-85.

36. Gasparovic H, Kopjar T, Biocina B. Letter by Gasparovic et al Regarding Article, "Surgical Ineligibility and Mortality Among Patients With Unprotected Left Main or Multivessel Coronary Artery Disease Undergoing Percutaneous Coronary Intervention". Circulation 2015;132:e155.

37. Levey AS, Stevens LA, Schmid CH, Zhang YL, Castro AF, 3rd, Feldman HI, Kusek JW, Eggers $\mathrm{P}$, Van Lente $\mathrm{F}$, Greene T and others. A new equation to estimate glomerular filtration rate. Ann Intern Med 2009;150:604-12. 


\section{Figure Legends:}

Figure 1: The percentage of percutaneous coronary interventions performed in surgically ineligible patients by hospital - The bar graph represents the percent of PCl cases performed in surgically ineligible patients in each hospital participating in the BMC2 registry. The sites are ordered from the lowest to the highest frequency site.

$\mathrm{PCl}=$ percutaneous coronary intervention

$P C$

Figure 2: In-hospital outcome rates in all patients - Bar graphs of primary and secondary inhospital outcomes in all patients stratified by ineligibility for surgery. The specific outcome rate is noted above each bar.

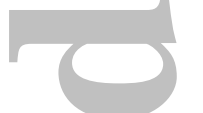

Figure 3: In-hospital outcome rates in the left main PCl subgroup - Bar graphs of primary and secondary in-hospital outcomes in patients who underwent left main PCl stratified by ineligibility for surgery. The specific outcome rate is noted above each bar.

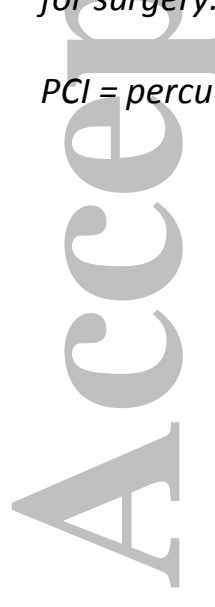


Table I: Baseline characteristics of surgically ineligible patients and others

\begin{tabular}{|c|c|c|c|}
\hline & Surgically & & \\
\hline & ineligible & Others & \\
\hline Variable & $(n=1,922)$ & ( $n=97,448)$ & $P$ value \\
\hline Age (years) & $64.5 \pm 11.8$ & $64.8 \pm 11.9$ & 0.30 \\
\hline Male & $63.5 \%$ & $63.8 \%$ & 0.80 \\
\hline Body mass index $\left(\mathrm{kg} / \mathrm{m}^{2}\right)$ & $30.9 \pm 7.8$ & $30.8 \pm 7.4$ & 0.69 \\
\hline Current/recent smoker & $30.4 \%$ & $28.5 \%$ & 0.08 \\
\hline Hypertension & $87.0 \%$ & $86.8 \%$ & 0.81 \\
\hline Dyslipidemia & $84.9 \%$ & $83.9 \%$ & 0.20 \\
\hline Diabetes mellitus & $37.8 \%$ & $37.9 \%$ & 0.97 \\
\hline Cerebrovascular disease & $14.3 \%$ & $14.2 \%$ & 0.92 \\
\hline Peripheral arterial disease & $15.9 \%$ & $14.6 \%$ & 0.12 \\
\hline Prior myocardial infarction & $35.2 \%$ & $32.1 \%$ & 0.004 \\
\hline Prior heart failure & $15.7 \%$ & $14.8 \%$ & 0.27 \\
\hline Prior valve surgery & $1.1 \%$ & $0.9 \%$ & 0.40 \\
\hline Prior $\mathrm{PCl}$ & $48.0 \%$ & $45.6 \%$ & 0.04 \\
\hline End-stage renal disease & $2.5 \%$ & $2.4 \%$ & 0.84 \\
\hline Chronic lung disease & $19.1 \%$ & $19.3 \%$ & 0.80 \\
\hline History of atrial fibrillation & $10.9 \%$ & $11.0 \%$ & 0.83 \\
\hline Current/recent gastrointestinal & $0.7 \%$ & $1.0 \%$ & 0.25 \\
\hline bleeding & & & \\
\hline Left ventricular ejection fraction & $53.6 \% \pm 12.0$ & $53.4 \% \pm 12.1$ & 0.56 \\
\hline Baseline creatinine $(\mathrm{mg} / \mathrm{dL})$ & $1.16 \pm 1.06$ & $1.14 \pm 0.99$ & 0.42 \\
\hline
\end{tabular}




\begin{tabular}{|c|c|c|c|}
\hline Baseline GFR $\left(\mathrm{ml} / \mathrm{min} / 1.73 \mathrm{~m}^{2}\right)^{*}$ & $74.97 \pm 24.30$ & $75.46 \pm 24.38$ & 0.39 \\
\hline Baseline hemoglobin $(\mathrm{g} / \mathrm{dL})$ & $13.42 \pm 1.80$ & $13.38 \pm 1.86$ & 0.24 \\
\hline Stable angina presentation & $17.1 \%$ & $16.5 \%$ & 0.48 \\
\hline Unstable angina presentation & $49.0 \%$ & $48.3 \%$ & 0.55 \\
\hline NSTEMI presentation & $24.3 \%$ & $25.4 \%$ & 0.28 \\
\hline Cardiogenic shock ${ }^{\dagger}$ & $1.0 \%$ & $0.8 \%$ & 0.20 \\
\hline $\mathrm{IABF}$ & $0.7 \%$ & $0.8 \%$ & 0.57 \\
\hline Non-IABP mechanical ventricular & $0.8 \%$ & $0.6 \%$ & 0.42 \\
\hline Chronic total occlusion treated & $3.5 \%$ & $3.0 \%$ & 0.20 \\
\hline Bifurcation lesion treated & $9.5 \%$ & $9.2 \%$ & 0.63 \\
\hline Pre-procedural predicted mortality & $0.57 \% \pm 2.28$ & $0.59 \% \pm 2.32$ & 0.69 \\
\hline risk" PCl-treated lesion** & $55.2 \%$ & $54.6 \%$ & 0.63 \\
\hline Emergent $\mathrm{PCl}$ & $2.3 \%$ & $2.1 \%$ & 0.50 \\
\hline \multicolumn{4}{|c|}{ All percentages represent frequencies, except for left ventricular ejection fraction and pre- } \\
\hline \multicolumn{4}{|c|}{ procedural predicted mortality risk, which are presented as mean \pm standard deviation. Where } \\
\hline \multicolumn{4}{|c|}{ nominal values are used, they are presented as mean \pm standard deviation. } \\
\hline \multicolumn{4}{|c|}{ GFR = glomerular filtration rate; $I A B P=$ intra-aortic balloon pump; NSTEMI = Non ST-elevation } \\
\hline \multicolumn{4}{|c|}{ myocardial infarction; $P C I=$ percutaneous coronary intervention } \\
\hline \multicolumn{4}{|c|}{ *The Chronic Kidney Disease Epidemiology Collaboration (CKD-EPI) equation was used (37). } \\
\hline tRepresents the frequency of patien & ardiogenic shock & n 24 hours prior & \\
\hline
\end{tabular}


$\S$ The pre-procedural risk of mortality was estimated using the BMC2 random forest prediction model available for review at https://bmc2.org/calculators/multi.

** Lesion characteristics consistent with a "Clesion" as defined by the NCDR CathPCI Registry (21).
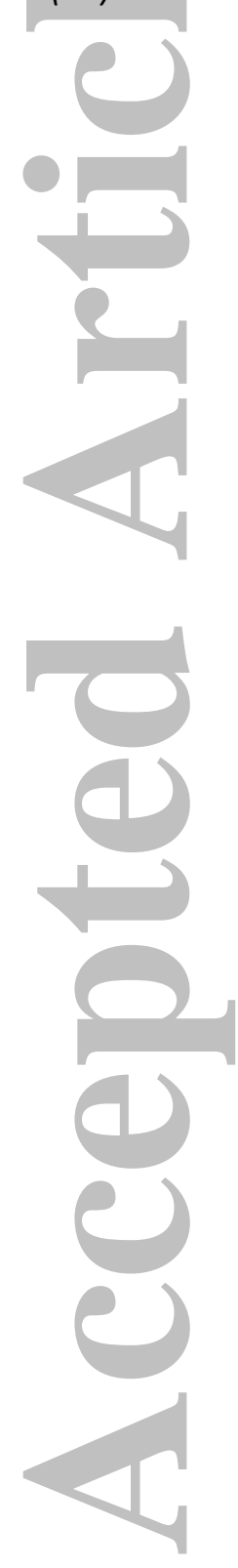

Catheterization and Cardiovascular Interventions

This article is protected by copyright. All rights reserved. 
Table II: Distribution of percutaneously treated coronary artery disease anatomy stratified by surgical ineligibility

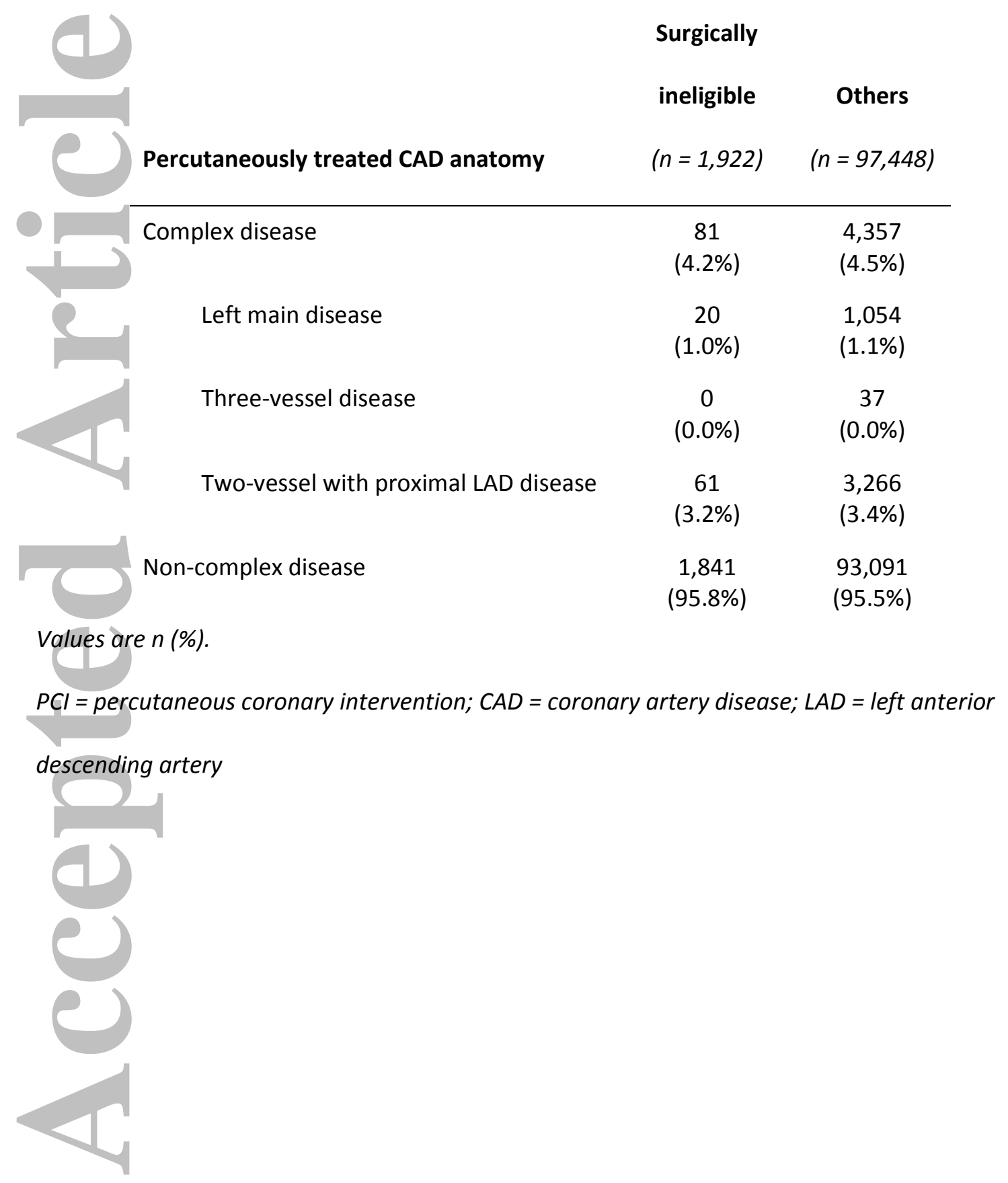


Figure 1:

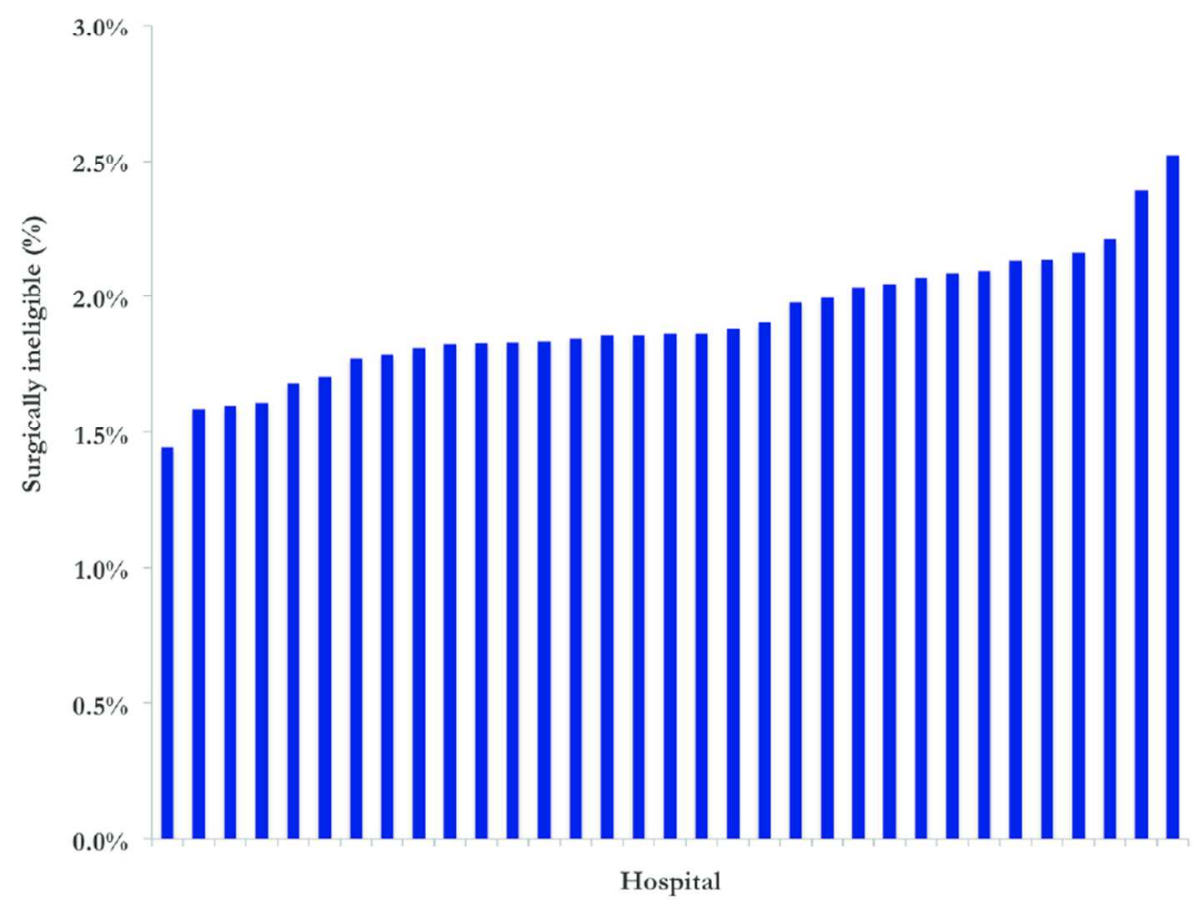

Figure 1: The percentage of percutaneous coronary interventions performed in surgically ineligible patients by hospital - The bar graph represents the percent of PCI cases performed in surgically ineligible patients in each hospital participating in the BMC2 registry. The sites are ordered from the lowest to the highest frequency site.

$\mathrm{PCI}=$ percutaneous coronary intervention

$85 \times 68 \mathrm{~mm}(300 \times 300$ DPI $)$

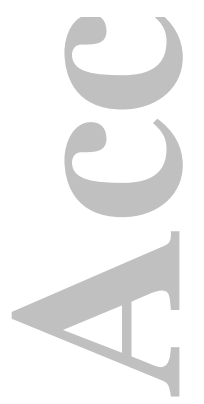




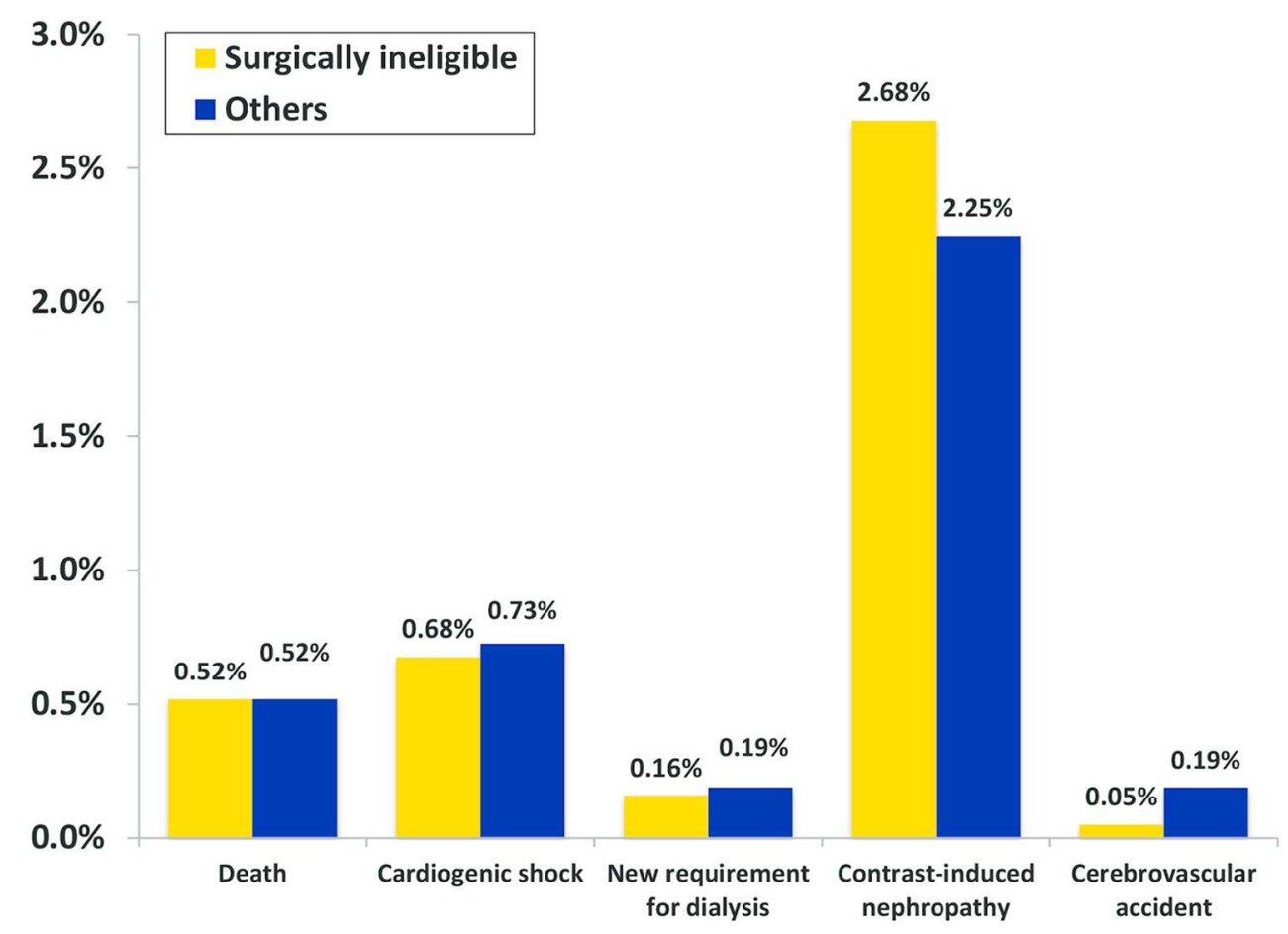

Figure 2: In-hospital outcome rates in all patients - Bar graphs of primary and secondary in-hospital outcomes in all patients stratified by ineligibility for surgery. The specific outcome rate is noted above each bar.

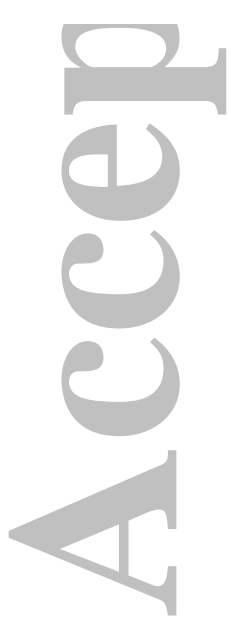

$128 \times 92 \mathrm{~mm}(300 \times 300$ DPI $)$ 
Figure 3:

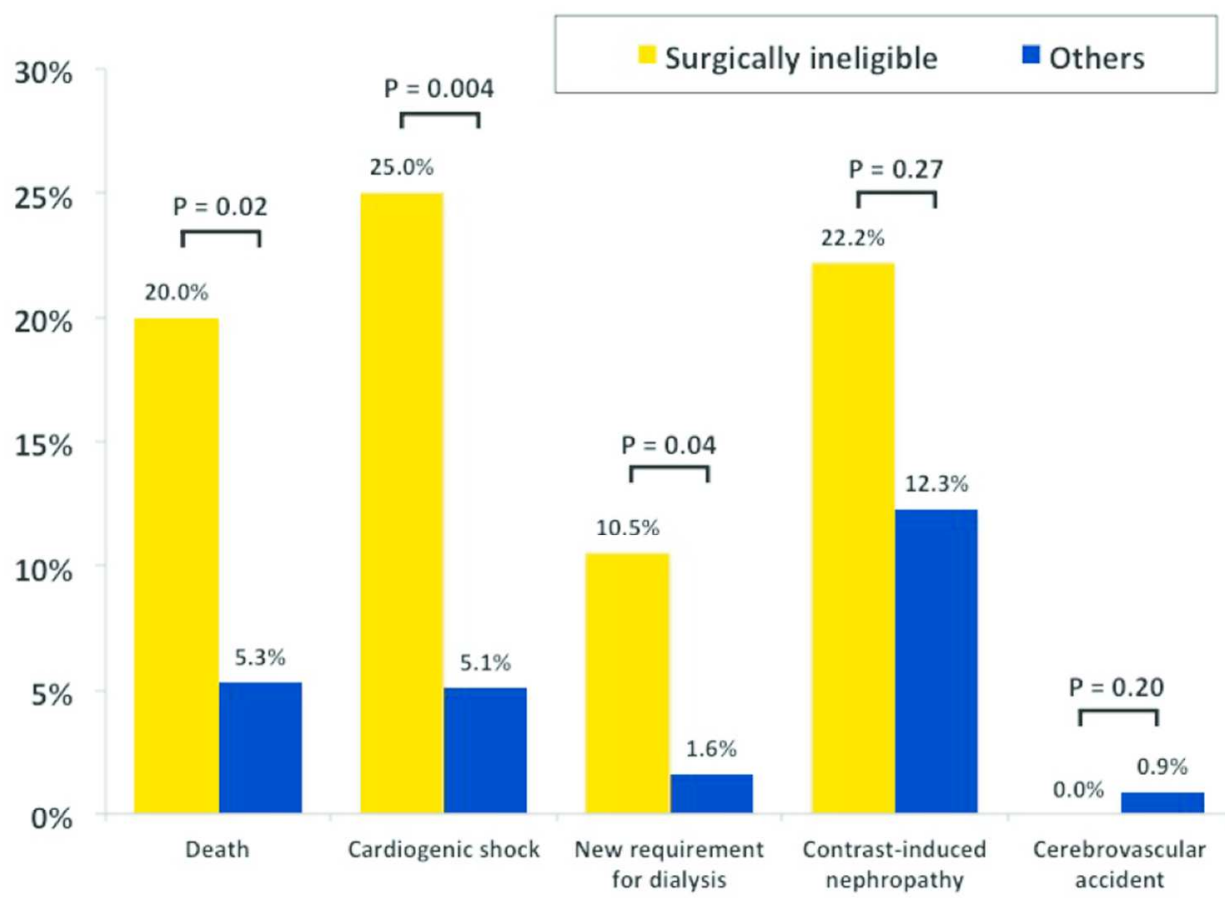

Figure 3: In-hospital outcome rates in the left main PCI subgroup - Bar graphs of primary and secondary inhospital outcomes in patients who underwent left main PCI stratified by ineligibility for surgery. The specific outcome rate is noted above each bar. ${ }_{\top}$ PCI = percutaneous coronary intervention ${ }_{\top}$

$84 \times 71 \mathrm{~mm}(300 \times 300 \mathrm{DPI})$ 
Referee(s)' Comments to Author:

\section{Reviewer: 1}

Comments to the Author In the present submission, "Clinical outcomes of percutaneous coronary intervention in patients turned down for surgical revascularization", Sukul et al., report results from a statewide registry suggesting that in-hospital outcomes among patients turned down for surgery and subsequently undergoing $\mathrm{PCl}$ are not significantly different as compared to outcomes in all other patients undergoing $\mathrm{PCl}$. The single exception is for surgically ineligible patients undergoing unprotected left main $\mathrm{PCl}$, who were observed to have higher mortality and other complications compared to surgically eligible patients undergoing left main PCl.

The manuscript is very well-written, and the analysis is sophisticated and appears to have been well-conducted. The authors' findings add insight to our understanding of the outcomes of $\mathrm{PCl}$ in surgically ineligible patients.

Suggestions for the authors:

1) The authors might clarify in the Abstract and throughout the manuscript that when they refer to left main $\mathrm{PCl}$ in this study, they are for the most part referring to unprotected left main $\mathrm{PCl}$, as patients with prior CABG were excluded. I suppose that an exception to this might be for patients with well formed collaterals to either the LAD or circumflex artery.

We appreciate the Reviewer bringing this to our attention. We have made changes to make it clear that left main PCl was unprotected in this study in the Abstract as well as on page 8 of the Methods:

"Complex disease was defined as unprotected left main PCl, three-vessel PCl, or two-vessel with proximal left anterior descending ( $L A D) P C l$. Due to the exclusion of patients with prior CABG, all left main PCls were considered unprotected."

2) The authors might also clarify in the Abstract that the analysis was limited to those centers with on-site surgical backup.

We have indicated in the Abstract that the PCls were performed at 33 hospitals with on-site surgical backup.

3) The authors might explicitly state in the Methods that patients undergoing staged PCI were not excluded from this analysis. They do discuss this point, and associated confounding, in the Discussion. Is it possible for the authors to identify patients undergoing staged $\mathrm{PCl}$ in this Registry, and analyze whether their exclusion changes the main findings?

Staged $\mathrm{PCl}$ procedures comprised 5,618 $(5.65 \%)$ of the cohort, of which $115(2.05 \%)$ were surgically ineligible. Among the staged $\mathrm{PCl}$ procedures, there were $0 / 115(0.00 \%)$ deaths in surgically ineligible cases, and $5 / 5,503(0.09 \%)$ among the remainder $(p=0.75$ for difference in mortality).

Per the Reviewer's request, we performed a supplementary analysis where staged PCI procedures were excluded from the cohort and a hierarchical generalized mixed effects regression model was fitted with the outcome of mortality adjusting for patient baseline mortality risk and PCl-treated CAD anatomy as fixed effects and accounting for potential hospital level variability through the inclusion of a hospital random intercept. The results were very similar to 
what was observed for the full cohort with a mortality odds ratio (surgically ineligible vs. nonineligible): $1.12(0.58-2.16), P=0.74$.

4) The authors do not mention any data regarding chronic total occlusion in this manuscript. Was this a variable in the registry? If so, it should be included as a marker of complex CAD. If not, the lack of data regarding CTO's should be mentioned as a limitation.

We defined complex coronary artery disease (CAD) using the appropriate use criteria for surgical revascularization in multivessel disease as a guide (1). Though this may be an imperfect definition of surgical coronary anatomy, we believe it is clinically applicable approach that has been used previously (2). We have included the complexity of the PCl-treated lesion to the baseline characteristics table, and below for your review. Of note, there is no significant difference in treated lesion complexity between surgically ineligible patients and the remainder.

\begin{tabular}{lccc} 
& $\begin{array}{c}\text { Surgically ineligible } \\
(\mathbf{n}=\mathbf{1 , 9 2 2})\end{array}$ & $\begin{array}{c}\text { Other } \\
(\mathbf{n = 9 7 , 4 4 8 )}\end{array}$ & P value \\
\hline Chronic total occlusion & $3.5 \%$ & $3.0 \%$ & 0.20 \\
Bifurcation lesion & $9.5 \%$ & $9.2 \%$ & 0.63
\end{tabular}

5) What strikes me is the lack of any significant difference in baseline variables between surgically ineligible and all other patients in this analysis (in my opinion the differences in prior $\mathrm{PCl}$ and prior MI do not achieve clinical significance). As such, it is not surprising that outcomes did not differ among these groups. I worry that there is significant confounding here - I would expect that surgically ineligible patients would be different in important ways from all other patients undergoing PCI. The confounder that seems most likely to me is incomplete capture of surgically ineligible patients by the registry. The fact that $98 \%$ of patients undergoing unprotected left main PCl were not surgically ineligible supports this possibility. The authors comment on this to a certain extent, and that surgically ineligible patients undergoing PCI may be "cherry picked," so to speak, but can they further discuss why they think the data demonstrate no differences in characteristics between these two groups?

We agree with the Reviewer. We were also surprised by the lack of substantial differences in characteristics between patients deemed surgically ineligible and the remainder. We speculate that some of this lack of difference is due to the utilization of informal (i.e. "curbside") consultations that are not documented in the medical record. It may also be because some patients were deemed surgical ineligible due, in part, to patient preference or an inappropriate indication for surgery. As noted above, understanding the reasons for surgical referral and ineligibility should be the focus of future research.

6) No patients deemed surgically ineligible underwent three vessel $\mathrm{PCl}$, which is surprising. Admittedly very few patients in the "all comers" cohort underwent three vessel $\mathrm{PCl}$ either. The authors discuss these findings to a certain point - staged PCI procedures, presence of CTO and completeness of revascularization were not accounted for. Given the small numbers and potential confounders related to these analyses, I wonder whether it would be better to simply report the findings from the overall cohorts and the left main $\mathrm{PCl}$ subgroups and remove the analysis of the "complex PCl" subgroup. Table 2 could then be eliminated as well. 
We agree with the Reviewer's observation and were similarly surprised by the data. However we believe that table 2 adds important information by providing a complete landscape of $\mathrm{PCl}$ practice. We feel that this should help engender further research into why these patients were referred for surgery in the first place and the reason(s) why $\mathrm{PCl}$ was performed on only one or two vessels.
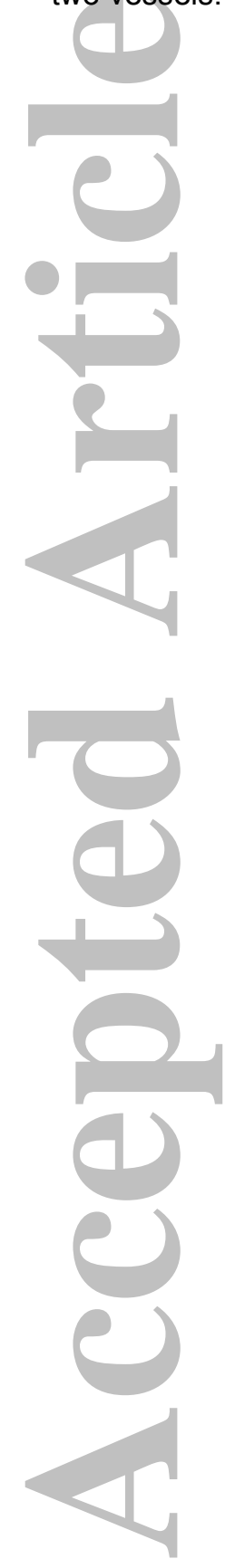
Reviewer: 2

\section{Comments to the Author}

The authors have conducted a retrospective, observational study of clinical outcomes in $\mathrm{PCl}$ patients deemed ineligible for surgery. The data is derived from a large, state-based registry, and the cohort number is impressively large. The authors report that clinical outcomes from this group are favorable, and there seems to be no penalty for $\mathrm{PCl}$ vs CABG. The notable exception is for patients having LMCA PCI, who did significantly worse. The general topic and findings are of interest to $\mathrm{PCl}$ operators, so I welcome this report. The data are well presented; the discussion is coherent and well written. Some specific comments below:

Why have peri-procedural MI and TLR-TVR not been included in the secondary endpoint? The death rate for LMCA PCI is high $(20 \%)$; were these cases performed with support of percutaneous LVAD? Did these patients die in the cathlab, or from systemic complications arising thereafter?

We thank the Reviewer for their insightful comments. Post-procedural myocardial infarction was not included as an endpoint due to the fact that only a select number of hospitals in this registry routinely check cardiac biomarkers after $\mathrm{PCl}$, whereas other sites check cardiac biomarkers at the discretion of the operator or based upon the clinical situation. This variability makes the endpoint subject to ascertainment (surveillance) bias, and likely results in an underrepresentation of the true post-procedural MI rate. Therefore, we do not believe it to be prudent to include this endpoint in our study. Furthermore, post-discharge outcomes such as TLR/TVR, are not tracked in this registry.

A modest proportion of patients undergoing left main $\mathrm{PCl}$ required mechanical support in the form of an intra-aortic balloon pump or other percutaneous device as depicted below. Importantly, there was no significant difference in the rate of mechanical support during PCl between surgically ineligible patients and the rest. We have included the number of patients who died in the catheterization lab in the table below at your request. Unfortunately, we are unable to discern the causes of in-hospital death, therefore, we do not know if patients died from systemic complications after discharge from the catheterization lab.

\begin{tabular}{lccc} 
& $\begin{array}{c}\text { Surgically ineligible } \\
(\mathbf{n = 2 0}\end{array}$ & $\begin{array}{c}\text { Other } \\
(\mathbf{n = 1 , 0 5 4 )}\end{array}$ & P value \\
\hline Intra-aortic balloon pump & $3 / 20(15.0 \%)$ & $\begin{array}{c}157 / 1,054 \\
(14.9 \%)\end{array}$ & 0.99 \\
Other mechanical ventricular support & $8 / 20(40.0 \%)$ & $\begin{array}{c}275 / 1,054 \\
(26.1 \%)\end{array}$ & 0.162 \\
Death in the catheterization lab & $0 / 20$ & $9 / 1,054$ & 0.68 \\
& $(0.0 \%)$ & $(0.85 \%)$ &
\end{tabular}

The authors detail the numerous limitations of the study. I am especially concerned regarding selection and reporting bias, which I appreciate is inherent in this type of registry study. In contemporary practice, surgical eligibility is generally determined by the "Heart Team", especially for high-risk patients. In this study, it was determined by a single cardiac surgeon, which introduces significant bias, further exacerbated by initial referral from a single primary physician (cardiologist). This issue should be acknowledged because there is a positive effect of Heart Team involvement in decision-making. The findings here cannot be extrapolated to centers (such as my own), which utilize a Heart Team. It would be interesting to know if surgery ineligible $\mathrm{PCl}$ patients who were vetted by their respective institutional Heart Teams, had better outcome than others. 
We agree with the Reviewer on their assessment of biases that may be playing a role in this study and is inherent to registry-based research assessing real-world practice. Nevertheless, we would like to point out that surgical ineligibility required documentation that a cardiac surgeon evaluated the patient and turned him or her down for surgical revascularization. This may have very well occurred in the context of a "Heart Team," though, as the Reviewer points out, it may also have been based upon the referral by a single cardiologist and a determination by a single cardiac surgeon.

Currently, we are unable to capture how the decision for surgical ineligibility is made (i.e. using a Heart Team approach or not), though it is interesting to note that there was very little variation in the frequency of $\mathrm{PCl}$ in surgically ineligible patients by hospital site. Understanding the rationale for both surgical referral and surgical ineligibility may provide one with a greater ability to risk stratify the surgically ineligible cohort, though unfortunately we did not collect this information as noted in the methods section. This should undoubtedly be an area of future research as emphasized in our discussion.

\section{$\mathrm{PCl}$ complexity would also include CTO and bifurcation cases, yet these seem not to be included.}

We defined complex coronary artery disease (CAD) using the appropriate use criteria for surgical revascularization in multivessel disease as a guide (1). We realize that this may be an imperfect definition for surgical coronary disease, but we believe it is a clinically applicable approach that has been used previously (2). We have included the complexity of the PCl-treated lesion to the baseline characteristics table, and below for your review.

\begin{tabular}{lccc} 
& $\begin{array}{c}\text { Surgically ineligible } \\
(\mathbf{n = 1 , 9 2 2})\end{array}$ & $\begin{array}{c}\text { Other } \\
(\mathbf{n = 9 7 , 4 4 8 )}\end{array}$ & P value \\
\hline Chronic total occlusion treated & $3.5 \%$ & $3.0 \%$ & 0.20 \\
Bifurcation lesion treated & $9.5 \%$ & $9.2 \%$ & 0.63
\end{tabular}

Left ventricular systolic impairment and diabetes would contribute to surgical ineligibility; conversely, prior PCI (implying stent failure for some) would be overall higher for the surgical group. Yet there were no differences for these parameter between the groups. Is there an explanation for these observations?

We were equally surprised by the lack of substantial differences in characteristics between patients deemed surgically ineligible and the remainder. As noted above, understanding the reasons for surgical referral and ineligibility should be the focus of future research. We believe that there may be substantial heterogeneity in the practice patterns dictating surgical referral and surgical ineligibility which requires further elucidation

Is it possible to show Kaplan-Meier survival curves?

Our registry only collects in-hospital data and no follow up data are available. Unfortunately given that our follow-up is of a relatively short duration, we do not believe a Kaplan-Meier survival curve would be useful. 


\section{Reviewer: 3}

\section{Comments to the Author}

The authors sought to compare in-hospital PCI clinical outcomes between surgically ineligible patients to the remainder $\mathrm{PCl}$ patients. The cohort is large and the question is relevant.

However, I have some concerns and suggestions:

- Abstract - A good and appealing abstract should contain all the important information: population (surgically ineligible patients), intervention ( $\mathrm{PCl}$ ), control group (others), outcome (in-hospital mortality, cardiogenic shock, CVA, CIN and NRD) and time (inhospital). Methods: specify primary and secondary outcomes. Results: specify what group is compared to the surgically ineligible patients.

We have revised the abstract to clearly delineate the pertinent information as stated above.

- Results (page 11, line 15) and discussion (page 12, line 22): left main $\mathrm{PCl}$ is known to have worse outcomes than less complex PCl. It is not clear in the text if the surgical ineligible left main $\mathrm{PCl}$ group was compared to the remainder left main $\mathrm{PCl}$ or to all the remainders (including less complex $\mathrm{PCl}$ ). Please specify.

We have separated that paragraph so as to draw attention to the left main $\mathrm{PCl}$ cohort. We compared outcomes between patients undergoing left main $\mathrm{PCl}$ who were surgically ineligible ( $\mathrm{n}$ $=20)$ as compared to those undergoing left main $\mathrm{PCl}$ who were not surgically ineligible $(\mathrm{n}=$ 1,054). I attempted to clarify this point in the text by stating that the comparison was "among patients who underwent left main $\mathrm{PCl}(\mathrm{n}=1,074)$ " and provided the number of patients who were surgically ineligible within that group $(n=20)$, and those that were not $(n=1,054)$.

- Conclusions: do not include references in the conclusions. Please be careful to state that left main $\mathrm{PCl}$ subgroup has a higher mortality rate because the study is underpowered for that issue $(n=20)$. The authors should be concise in this section. All inferences and thoughts should be included in the discussion section.

Thank you for your insightful comment. We have removed references and inferences from the conclusion. Furthermore, we have clarified the finding of increased mortality in surgically ineligible patients undergoing left main $\mathrm{PCl}$ in the following sentence:

"Importantly though, there is a substantial effect of surgical ineligibility on mortality in the subgroup of patients who underwent left main PCl, although this finding should be interpreted with caution as only 20 surgically ineligible patients underwent left main PCl."

Table I: What was the score used to predict mortality risk? Please specify in a footnote.

-We have added a footnote to Table I specifying the BMC2 mortality risk prediction model utilized in this study and available for review at: https://bmc2.org/calculators/multi.

- Figure 1 shows irrelevant information. Please reconsider including it.

We respectfully disagree with the Reviewer and believe that this figure graphically demonstrates that our findings are not a function of specific hospitals with unusual practices, but instead driven by similar practices across heterogeneous institutions. 
- Figure 3: please specify the $p$ value on top of each bar group.

We have included the exact p-value for each comparison in Figure 3.
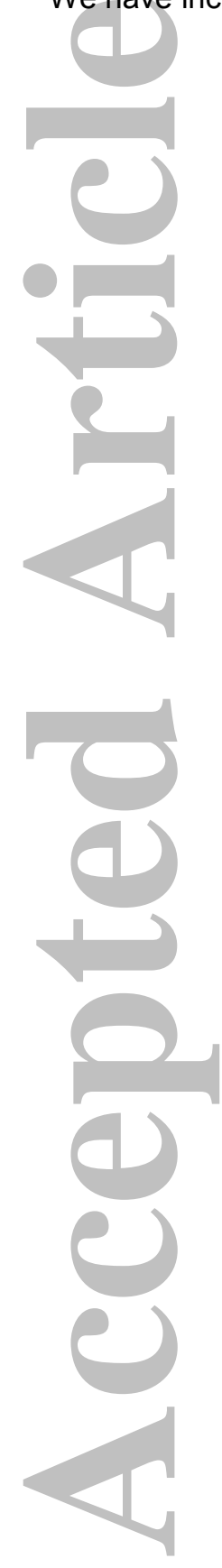

Catheterization and Cardiovascular Interventions

This article is protected by copyright. All rights reserved. 


\section{REFERENCES}

1. Patel MR, Dehmer GJ, Hirshfeld JW, Smith PK, Spertus JA. ACCF/SCAI/STS/AATS/AHA/ASNC/HFSA/SCCT 2012 Appropriate use criteria for coronary revascularization focused update: a report of the American College of Cardiology Foundation Appropriate Use Criteria Task Force, Society for Cardiovascular Angiography and Interventions, Society of Thoracic Surgeons, American Association for Thoracic Surgery, American Heart Association, American Society of Nuclear Cardiology, and the Society of Cardiovascular Computed Tomography. J Am Coll Cardiol 2012;59:857-81.

2. Waldo SW, Secemsky EA, O'Brien C, Kennedy KF, Pomerantsev E, Sundt TM, 3rd, McNulty EJ, Scirica BM, Yeh RW. Surgical ineligibility and mortality among patients with unprotected left main or multivessel coronary artery disease undergoing percutaneous

coronary intervention. Circulation 2014;130:2295-301.

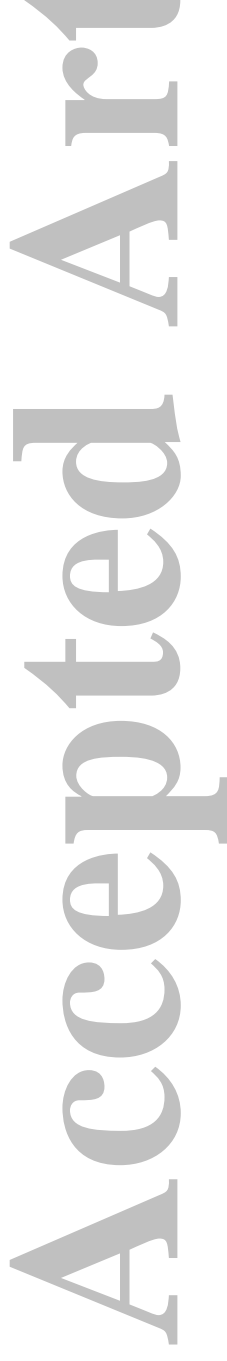




\section{Clinical Outcomes of Percutaneous Coronary Intervention in Patients Turned Down for Surgical Revascularization}

Running Title: PCl Outcomes in Patients Turned Down for Surgery

Devraj Sukul, MD푸 Milan Seth, $\mathrm{MS}^{1}$; Simon R. Dixon, $\mathrm{MBChB}^{2}$; Mark Zainea, $\mathrm{MD}^{3}$; Nicklaus K. Slocum, MD ; Elizabeth J. Pielsticker, MD $^{5}$; Hitinder S. Gurm, MD ${ }^{1,6}$

${ }^{1}$ Department of Internal Medicine, Division of Cardiovascular Medicine, University of Michigan, Ann Arbor, Michigan, ${ }^{2}$ William Beaumont Hospital, Heart and Vascular, Royal Oak, MI, ${ }^{3}$ McLaren Macomb Hospital, Roseville, MI, ${ }^{4}$ Traverse Heart \& Vascular, Traverse City, MI, ${ }^{5}$ St Joseph Mercy Health System, Michigan Heart, Jackson, MI, ${ }^{6}$ Veterans Affairs Medical Center, Ann Arbor, MI

Support:

Support for BMC2 is provided by Blue Cross and Blue Shield of Michigan and Blue Care Network as part of the BCBSM Value Partnerships program.

Disclaimer: Although Blue Cross Blue Shield of Michigan and BMC2 work collaboratively, the opinions, beliefs and viewpoints expressed by the author do not necessarily reflect the opinions, beliefs and viewpoints of BCBSM or any of its employees.

\section{Conflict of Interest/Disclosures:}

Hitinder S. Gurm receives research funding from Blue Cross Blue Shield of Michigan, the National Institutes of Health and is a consultant for Osprey Medical. None of the authors have any conflicts directly relevant to this study.

\section{Corresponding Author:}

Hitinder S. Gurm, MD

2A 394, 1500 East Medical Ctr Drive, University of Michigan Cardiovascular Center Ann Arbor, MI 48109-5853 hgurm@med.umich.edu Word Count: 4255 


\section{STRUCTURED ABSTRACT:}

OBJECTIVES: We examined clinical outcomes following percutaneous coronary intervention $(\mathrm{PCl})$ in patients turned down for surgical revascularization across a broad population.

BACKGROUND: Prior studies suggest that surgical ineligibility is associated with increased mortality in patients with unprotected left main or multivessel coronary artery disease undergoing $\mathrm{PCl}$.

METHODS: This study included consecutive patients who underwent $\mathrm{PCl}$ in a multicenter registry in Michigan from 1/2010 - 12/2014. Surgical ineligibility required documentation indicating that a cardiac surgeon deemed the patient ineligible for surgery. In-hospital outcomes included mortality (primary outcome), cardiogenic shock, cerebrovascular accident, contrastinduced nephropathy (CIN), and a new requirement for dialysis (NRD).

RESULTS: Of 99,370 patients at 33 hospitals with on-site surgical backup, 1,922 (1.9\%) were surgically ineligible. The rate of ineligibility did not vary by hospital (range: $1.5 \%-2.5 \% ; p=0.79$ ).

Overall, there were no major differences in baseline characteristics or outcomes between surgically ineligible patients and the rest (i.e. non-ineligible patients): mortality $(0.52 \%$ vs.

$0.52 \% ; p>0.5)$, cardiogenic shock $(0.68 \%$ vs. $0.73 \% ; p>0.5)$, cerebrovascular accident $(0.05 \%$ vs. $0.19 \% ; p=0.28), \operatorname{NRD}(0.16 \%$ vs. $0.19 \% ; p>0.5)$, CIN (2.7\% vs. $2.3 \% ; p=0.27)$. Among 1,074 patients who underwent unprotected left main $\mathrm{PCl}, 20$ (1.9\%) were surgically ineligible and experienced increased rates of mortality ( $20.0 \%$ vs. $5.3 \% ; p=0.022 ;$ adjusted $O R=7.38 ; p<0.001)$ and other complications as compared to the remainder.

CONCLUSIONS: $\mathrm{PCI}$ in a broad population of surgically ineligible patients is generally safe. However, among patients who underwent unprotected left main $\mathrm{PCl}$, those deemed surgically ineligible experienced significantly worse outcomes as compared to the rest. 
KEY WORDS: percutaneous coronary intervention (PCI); coronary artery bypass grafting; health care outcomes; risk stratification; coronary artery disease ABSTRACT WORD COUNT: 247 (limit 250)
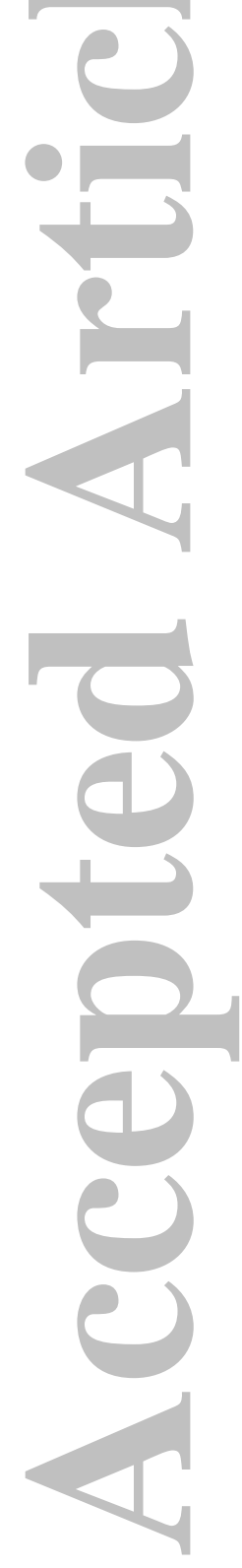

Catheterization and Cardiovascular Interventions

This article is protected by copyright. All rights reserved. 
CONDENSED ABSTRACT: Using a large, multicenter, regional registry of $\mathrm{PCl}$, this study examined the relationship between surgical ineligibility and clinical outcomes after $\mathrm{PCl}$. In the overall study cohort $(n=99,370), \mathrm{PCl}$ appears to be safe in surgically ineligible patients as there was no significant difference in outcomes between ineligible patients as compared to the rest. Importantly, surgical ineligibility was associated with worse outcomes in patients undergoing unprotected left main $\mathrm{PCl}$.
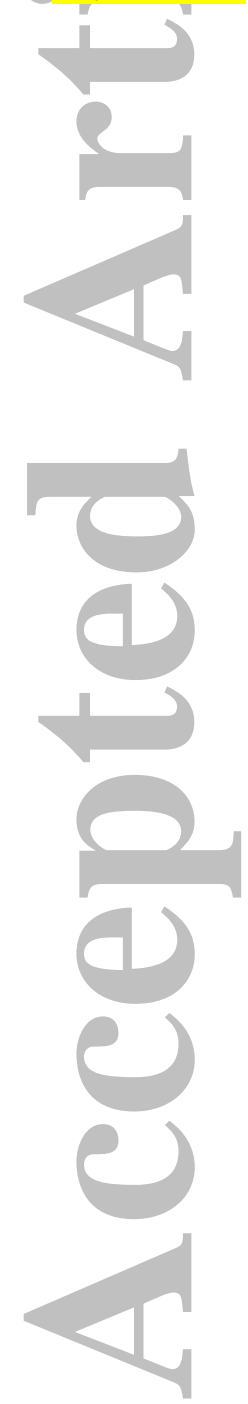


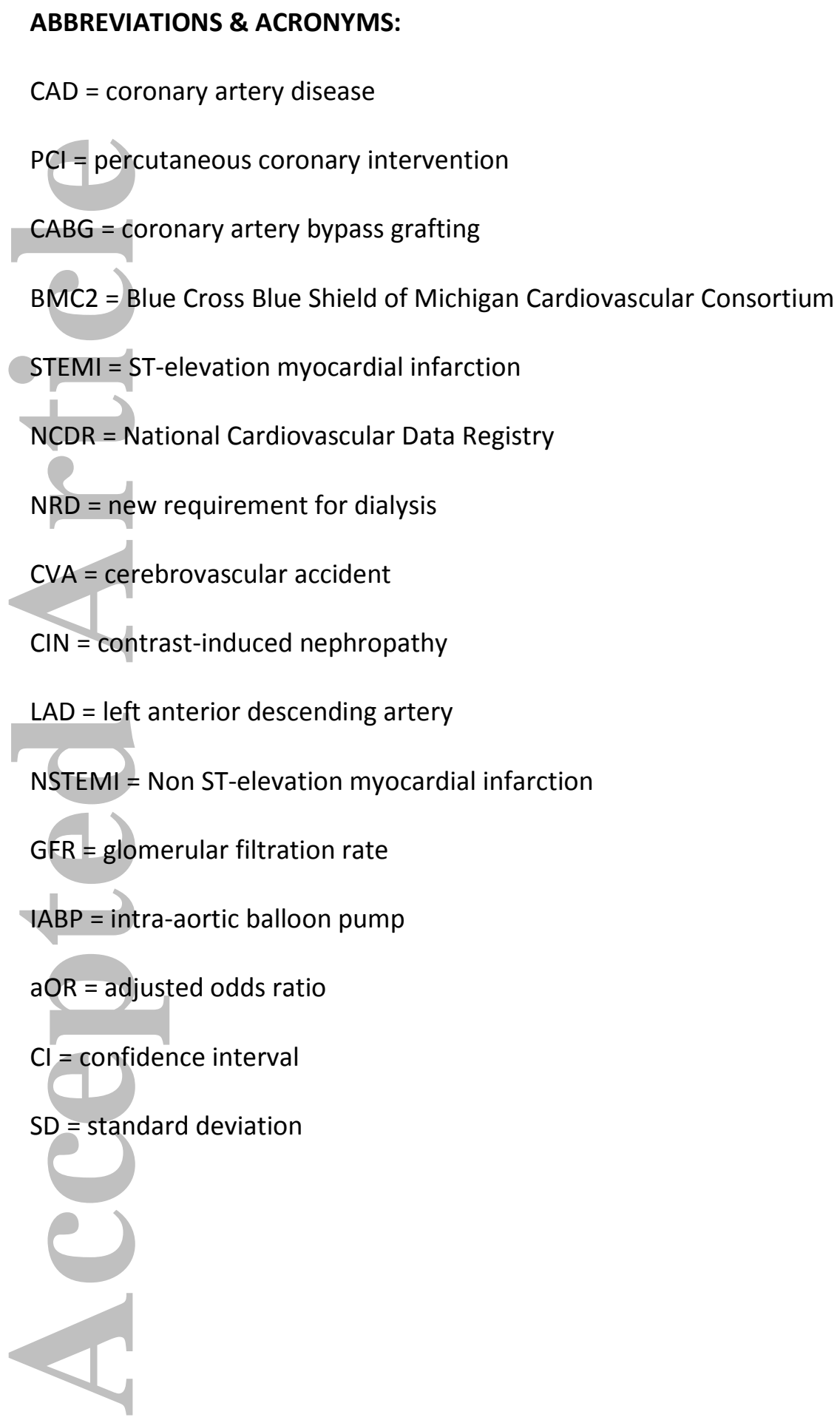




\section{INTRODUCTION}

The optimal method of revascularization for coronary artery disease (CAD), whether it is percutaneous coronary intervention ( $\mathrm{PCl}$ ) or coronary artery bypass grafting (CABG), has been a controversial and frequent topic of research for many years (1-12). Physicians consider numerous factors when formulating their recommendation for revascularization, including, but not limited to, the presence of diabetes mellitus, chronic kidney disease, systolic dysfunction, prior CABG, and the complexity of CAD (13-15). In recent years, clinical guidelines and appropriate use criteria have been developed to assist physicians in making evidence-based recommendations $(13,14,16)$.

Nevertheless, the decision to recommend surgical or percutaneous revascularization is complex, frequently requiring the input of general cardiologists, interventional cardiologists, and cardiac surgeons. Clinical guidelines advocate for a team-based, multidisciplinary, "Heart Team" approach to determining the optimal revascularization strategy for complex patients $(13,14,16)$. Through this multidisciplinary approach, patients may be deemed ineligible for a particular revascularization option.

Recent research has demonstrated that patients with unprotected left main or multivessel CAD who are deemed ineligible for surgical revascularization experience worse outcomes after $\mathrm{PCl}$ as compared to patients not deemed ineligible $(17,18)$. These studies reflect the experiences of $\mathrm{PCl}$ at tertiary care institutions. Historically, surgically ineligible patients referred for $\mathrm{PCl}$ are thought to represent a high-risk cohort. The characteristics and outcomes of $\mathrm{PCl}$ in patients turned down for surgical revascularization in broad community practice have not been studied. Therefore, using a large regional PCl database, we sought to describe the characteristics and outcomes of $\mathrm{PCl}$ in patients with documented surgical ineligibility within a diverse array of $\mathrm{PCl}$-capable hospitals. 


\section{METHODS}

We performed a retrospective analysis on data from the Blue Cross Blue Shield of Michigan Cardiovascular Consortium (BMC2), a regional registry of all patients undergoing $\mathrm{PCl}$ in Michigan. A more complete description of the registry, including data collection and auditing practices, has been described previously $(19,20)$. Briefly, this is a prospective, multicenter, statewide registry of patients undergoing $\mathrm{PCl}$ at any of the non-federal hospitals in Michigan. For the current study, consecutive patients undergoing PCI between January 2010 and December 2014 at the 33 hospitals with on-site cardiac surgery were included.

Patients that presented with ST-elevation myocardial infarction (STEMI) or preprocedural cardiac arrest were excluded due to the emergent nature of treatment and a bias towards $\mathrm{PCl}$ in these individuals. Patients with a history of CABG were excluded, as the decision to recommend surgical or percutaneous revascularization often hinges on unique and important considerations such as repeat sternotomy, graft anatomy, and conduit availability. Finally, patients that underwent salvage $\mathrm{PCl}$ were excluded given the use of $\mathrm{PCl}$ as a last resort in these critically ill patients. Salvage $\mathrm{PCl}$ was defined as $\mathrm{PCl}$ in a patient who, within ten minutes prior to the start of the procedure, has received chest compressions or has been on unanticipated extracorporeal circulatory support (21). Surgical ineligibility was defined as written documentation indicating that the patient was evaluated by a cardiac surgeon and felt not to be a surgical candidate for any reason. We did not collect information regarding the reason for surgical referral or for surgical ineligibility, as these reasons are often heterogeneous and poorly defined. We divided patients into two groups, those turned down for surgical revascularization and the remainder (who may or may not have been evaluated by a cardiac surgeon).

\section{Outcomes and Subgroup Analysis}


All outcomes were measured during the incident hospitalization when $\mathrm{PCl}$ was

performed. The primary outcome measure was in-hospital mortality attributable to any cause.

Secondary outcomes included the development of post-procedure cardiogenic shock,

cerebrovascular accident (CVA), contrast-induced nephropathy (CIN), and a new requirement for dialysis (NRD). Post-procedure cardiogenic shock and CVA were defined as per the NCDR

CathPCI registry definition (21). CIN was defined as renal dysfunction resulting in a $0.5 \mathrm{mg} / \mathrm{dL}$ absolute increase in a post-procedure creatinine measurement as compared to baseline. NRD was defined as any new, unplanned need for dialysis after PCI.

Clinical outcomes are reported for the overall cohort and by subgroups defined by percutaneously treated CAD anatomy. Diagnostic catheterization data were not routinely collected on all patients in the registry; therefore, we defined CAD anatomy by the site(s) of $\mathrm{PCI}$ per catheterization lab visit. Complex disease was defined as unprotected left main $\mathrm{PCl}$, threevessel $\mathrm{PCl}$, or two-vessel with proximal left anterior descending (LAD) PCI. Due to the exclusion of patients with prior CABG, all left main PCls were considered unprotected. The hierarchy of categorization also followed the aforementioned sequence. For example, a patient who underwent left main and proximal LAD PCI would be classified as having left main disease, not two-vessel with proximal LAD disease. All other patients were categorized as having noncomplex disease.

\section{Statistical Analysis}

Baseline characteristics and outcomes were compared between surgically ineligible patients and the remainder using Pearson $\chi 2$ or Fisher's exact test for categorical variables and Student $t$-tests for continuous variables. Continuous variables were summarized using mean \pm SD. Outcome rates by surgical ineligibility were compared using Fisher's exact test. Pre- 
procedural risks of mortality, $\mathrm{CIN}$, and need for transfusion were estimated using the BMC2 random forest prediction models (available for review at https://bmc2.org/calculators/multi). The methodology and specific implementations for CIN and transfusion endpoints have been validated and previously described elsewhere $(22,23)$.

For the primary outcome of mortality, hierarchical logistic regression models were utilized incorporating patient baseline mortality risk and PCI-treated CAD anatomy as fixed effects and

effects and accounting for potential hospital level variability through the inclusion of a hospital random intercept. All analyses were performed using R version 3.2.1 (24). Hierarchical generalized mixed effects regression models were fitted using the Ime4 R package (25).

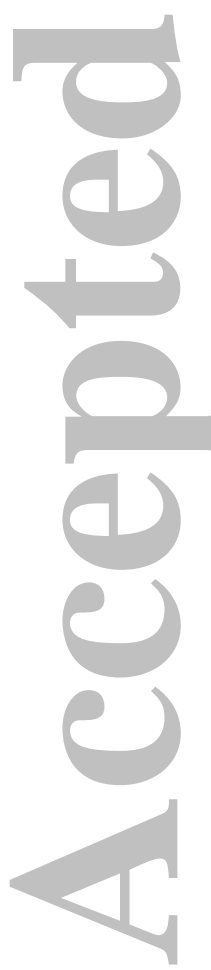




\section{RESULTS}

A total of 151,223 patients underwent $\mathrm{PCl}$ at the 33 participating centers between January 2010 and December 2014. Of these, 24,153 (16.0\%) presented with STEMI, 2,893 (1.9\%) experienced a pre-procedure cardiac arrest, $283(0.2 \%)$ underwent salvage $\mathrm{PCl}$, and 28,242 (18.7\%) had a history of CABG. A total of 51,853 (34.3\%) patients met at least one exclusion criteria, leaving 99,370 patients in the overall cohort. A total of 1,922 (1.9\%) patients were turned down for surgery. The baseline characteristics of surgically ineligible patients and the remainder are presented in Table 1 . The two groups were largely similar in their baseline characteristics, with only prior myocardial infarction and prior $\mathrm{PCl}$ having occurred at a greater frequency in patients ineligible for surgery.

There was no significant site-level variation in the incidence of surgically ineligible patients across the 33 hospitals with on-site surgical backup (range: $1.5 \%$ to $2.5 \% ; X^{2}=25.5$ on $32 \mathrm{df} ; \mathrm{p}>0.5$ ) (Figure 1). In-hospital mortality was similar between the two groups $(0.52 \%$ vs. (1)

$0.52 \% ; p>0.5$; Figure 2), and no significant difference was observed after adjusting for preprocedural predicted risk of mortality, $\mathrm{PCl}$-treated CAD anatomy, and hospital-level clustering in a hierarchical regression model (adjusted odds ratio $[\mathrm{aOR}]=1.11 ; 95 \%$ confidence interval $[\mathrm{Cl}]$ $0.57-2.15 ; p>0.5)$. Furthermore, no significant differences were noted in secondary outcome measures (Figure 2).

Stratification by PCI-treated CAD anatomy A total of 4,438 patients were defined as having complex disease, of which 81 patients (1.8\%) had documentation of surgical ineligibility. The majority $(95.8 \% ; n / N=1,841 / 1,922)$ of surgically ineligible patients had non-complex disease (Table 2). There was no difference in the distribution of $\mathrm{PCl}$-treated $\mathrm{CAD}$ anatomy between patients turned down and not turned down 
for surgery $(p>0.5)$. Of note, no surgically ineligible patients underwent three-vessel PCI. No significant differences in primary or secondary outcomes were observed in any PCI-treated CAD anatomy subgroup other than left main $\mathrm{PCl}$ patients.

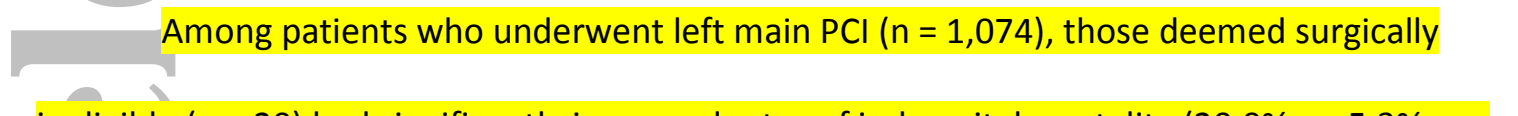
ineligible $(n=20)$ had significantly increased rates of in-hospital mortality $(20.0 \%$ vs. $5.3 \% ; p=$ $0.022)$, cardiogenic shock ( $25.0 \%$ vs. $5.1 \% ; p=0.004)$, and NRD $(10.5 \%$ vs. $1.6 \% ; p=0.042)$ as compared to the remainder ( $n=1,054$; Figure 3$)$. Of note, $40 \%(n / N=4 / 10)$ of in-hospital deaths in all surgically ineligible patients occurred in those who underwent left main PCI.

The effect of surgical ineligibility on mortality varied significantly between patients with left main PCl compared to those with other PCI-treated CAD anatomy after adjusting for predicted pre-procedural mortality risk, CAD anatomy, and hospital-level clustering (Likelihood ratio test for left main $\mathrm{PCl}$ by ineligibility interaction: $\mathrm{LRT}=12.7$ on $1 \mathrm{df}, \mathrm{p}<0.0001$ ). In stratified, adjusted hierarchical regression analysis, again adjusting for predicted baseline risk and hospital level clustering fit within the left main $\mathrm{PCl}$ subgroup, mortality was strongly associated with surgical ineligibility $(\mathrm{aOR}=7.38,95 \% \mathrm{Cl} 2.32-23.49, \mathrm{p}<0.001)$. 


\section{DISCUSSION}

Recent research has demonstrated that surgical ineligibility is associated with inferior outcomes after $\mathrm{PCl}$ in patients with complex $\operatorname{CAD}(17,18)$. Our study significantly adds to this body of literature through three major findings. First, it appears that broadly, $\mathrm{PCl}$ in patients deemed ineligible for surgical revascularization is safe, given that there is no significant difference in multiple, clinically relevant, in-hospital outcomes including death. Second, as noted in prior studies, individuals who were deemed ineligible for surgery and underwent left main PCI suffered significantly worse outcomes as compared to the rest of the cohort, highlighting the potential additive effect of surgical ineligibility in high-risk, complex $\operatorname{CAD}(17,18)$. Third, there was no significant variation in the frequency of $\mathrm{PCl}$ in surgically ineligible patients amongst a diverse group of $\mathrm{PCl}$-capable hospitals within this region.

Though $\mathrm{PCl}$ in patients with documented surgical ineligibility appears to be safe, these findings must be interpreted with certain caveats. One potential reason why $\mathrm{PCl}$ appears safe in this population may be because these surgically ineligible patients were inherently deemed eligible for $\mathrm{PCl}$ by the interventional cardiologist performing the procedure. Undoubtedly, there are patients who are deemed ineligible for surgery and $\mathrm{PCl}$, thereby never undergoing revascularization. The outcomes of these patients were not collected or reported.

When assessing the outcomes of $\mathrm{PCl}$ by $\mathrm{PCl}$-treated $\mathrm{CAD}$ anatomy, we attempted to classify patients according to the severity of their disease by using the appropriate use criteria for multivessel disease as a guide (16). Patients who underwent two-vessel with proximal LAD $\mathrm{PCl}$ experienced similar outcomes when stratified by surgical ineligibility. There is a possibility that this finding is due to misclassification of CAD complexity, given that we classified CAD anatomy based on lesions treated by $\mathrm{PCl}$ and not native $\mathrm{CAD}$ at the time of diagnostic 
catheterization. Therefore, patients with multivessel complex CAD who underwent staged PCI may have been categorized as having non-complex disease. Additionally, some patients with multivessel native CAD would have been categorized as having non-complex disease if they underwent $\mathrm{PCl}$ of select lesions (i.e. incomplete revascularization), if the interventional cardiologist felt that this would provide the optimal risk/benefit ratio. Nevertheless, the generally favorable outcomes in the overall population are reassuring.

Though only 20 surgically ineligible patients underwent left main PCI, 4 (20\%) died during the hospitalization. This surgically ineligible subgroup also had increased rates of cardiogenic shock and NRD. Even after adjustment, surgical ineligibility was associated with a 7fold increase in in-hospital mortality in this subgroup. Although the absolute number of patients in this subgroup is small, this finding is consistent with prior studies assessing the relationship between surgical ineligibility and $\mathrm{PCl}$ outcomes $(17,18)$. Future studies should attempt to elucidate the specific, and often complex, reasons for surgical ineligibility that may confer this increased risk. It is also noteworthy that a substantially larger number of patients underwent left main $\mathrm{PCl}$ without being turned down for surgery and the general outcome in this cohort was excellent. Although the total number of patients who were referred to surgery for left main disease is not available, it is likely that these 20 patients represent a highly selected and unique subset of patients who were at a high risk of adverse outcomes from either revascularization strategy.

Multiple studies have demonstrated significant hospital-level variation for a number of important cardiovascular outcomes (26-28). The 33 nonfederal PCl-capable hospitals in our statewide registry vary from community hospitals to quaternary teaching hospitals. We found no significant difference in the rate of $\mathrm{PCl}$ in surgically ineligible patients across these hospitals. This suggests that practice patterns are broadly similar across the state. Notably, both 
interventional cardiologists and cardiac surgeons participate in statewide collaborative quality improvement initiatives and such practice uniformity may or may not exist across geographic regions that do not participate in such initiatives (29).

Clinical guidelines advocate for the use of a multidisciplinary Heart Team approach when evaluating revascularization options for patients with complex CAD $(13,14,16)$. Therefore, it is surprising that the vast majority of surgically ineligible patients $(95.8 \%)$ had non-complex disease. As stated above, this number may be an overestimate due to our classification scheme. Nevertheless, even if we were to assume a substantial proportion of misclassification, the majority of patients would still likely have non-complex disease. It is unclear why these patients were referred for surgery, let alone deemed ineligible. It is possible that these patients may have had more diffuse and complex coronary lesions or other cardiac conditions such as severe valve disease that may have led to surgical referral. In the future, the number of patients with complex CAD evaluated for surgical and percutaneous revascularization options will likely increase as the utilization of a Heart Team approach grows (30-32). We suspect that documentation of these collaborative decisions will provide a better understanding of referral practices between cardiologists and cardiac surgeons and allow for more rigorous research into the effects of surgical ineligibility on patient outcomes.

Fortunately, through the emergence of new healthcare information technologies and the mandate for the meaningful use of electronic health records, "big data" analytics may be able to help us better understand these issues in the future. For example, the application of natural language processing systems to electronic medical records have already resulted in improved prediction and detection of outcomes, and is being used to develop clinical registries (33-35). We imagine that the application of these technologies to the vast wealth of clinical information in electronic health records will ultimately allow us to obtain a more complete and

\section{Catheterization and Cardiovascular Interventions}

This article is protected by copyright. All rights reserved. 
nuanced understanding of complex clinical decisions such as the reasons for surgical referral and the rationale for surgical ineligibility (or eligibility) in patients with CAD.

There are several limitations in our study that deserve specific mention. First, as noted above, we may have potentially misclassified the complexity of CAD due to inherent limitations in the accurate collection of native CAD anatomy, requiring us to use percutaneously treated CAD anatomy. Second, the registry follows a rigorous definition for surgical ineligibility, and surgical ineligibility cannot be assigned by a cardiologist or following a "curbside" consult. We had no method of accounting for non-documented surgical ineligibility, but our rigorous definition would increase the specificity of our findings. Furthermore, as noted by Gasparovic et al, we believe that in order to accurately study the association between surgical ineligibility and $\mathrm{PCl}$ outcomes, cardiac surgeons, not surrogate decision-makers, should determine a patient's eligibility for surgery (36). Third, we do not have data on intermediate- and long-term outcomes. As demonstrated previously, there may be a more substantial difference in outcomes between these two groups in the long-term $(17,18)$. Fourth, despite collecting PCl information from multiple centers over a 4-year time period, our statistical power to detect significant differences in outcomes was limited by the small number of patients deemed surgically ineligible. This limitation underscores the need for ongoing research studying the impact of surgical ineligibility on $\mathrm{PCl}$ outcomes, and the consideration of including this variable in large, national $\mathrm{PCl}$ registries.

\section{CONCLUSIONS}

$\mathrm{PCl}$ in a broad population of surgically ineligible patients appears safe, potentially highlighting the discretion utilized by interventional cardiologists in selecting these patients. Importantly though, there is a substantial effect of surgical ineligibility on mortality in the subgroup of patients who underwent unprotected left main $\mathrm{PCl}$, although this finding should be

\section{Catheterization and Cardiovascular Interventions}

This article is protected by copyright. All rights reserved. 
interpreted with caution as only 20 surgically ineligible patients underwent left main $\mathrm{PCI}$. Our findings may assist physicians and patients in more accurately estimating the risks associated with $\mathrm{PCl}$ in patients with documented surgical ineligibility.

\section{ACKNOWLEDGEMENTS:}

The authors are indebted to all the study coordinators, investigators, and patients who participated in the Blue Cross Blue Shield of Michigan Cardiovascular Consortium registry.
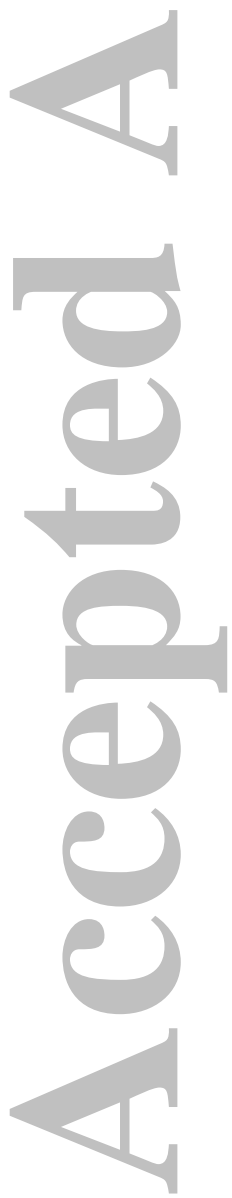

Catheterization and Cardiovascular Interventions

This article is protected by copyright. All rights reserved. 


\section{REFERENCES}

1. Al Ali J, Franck C, Filion KB, Eisenberg MJ. Coronary artery bypass graft surgery versus percutaneous coronary intervention with first-generation drug-eluting stents: a metaanalysis of randomized controlled trials. JACC Cardiovasc Interv 2014;7:497-506.

2. Comparison of coronary bypass surgery with angioplasty in patients with multivessel disease. The Bypass Angioplasty Revascularization Investigation (BARI) Investigators. N Engl J Med 1996;335:217-25.

3. Chieffo A, Magni V, Latib A, Maisano F, lelasi A, Montorfano M, Carlino M, Godino C, Ferraro $\mathrm{M}$, Calori $\mathrm{G}$ and others. 5-year outcomes following percutaneous coronary intervention with drug-eluting stent implantation versus coronary artery bypass graft for unprotected left main coronary artery lesions the Milan experience. JACC Cardiovasc Interv 2010;3:595-601.

4. Deb S, Wijeysundera HC, Ko DT, Tsubota H, Hill S, Fremes SE. Coronary artery bypass graft surgery vs percutaneous interventions in coronary revascularization: a systematic review. JAMA 2013;310:2086-95.

5. Fukui T, Tabata M, Tobaru T, Asano R, Takanashi S, Sumiyoshi T. Early and long-term outcomes of coronary artery bypass grafting and percutaneous coronary intervention in patients with left main disease: single-center results of multidisciplinary decision making. Gen Thorac Cardiovasc Surg 2014;62:301-7.

6. Hamm CW, Reimers J, Ischinger T, Rupprecht HJ, Berger J, Bleifeld W. A randomized

study of coronary angioplasty compared with bypass surgery in patients with symptomatic multivessel coronary disease. German Angioplasty Bypass Surgery

Investigation (GABI). N Engl J Med 1994;331:1037-43.

7. Hannan EL, Zhong Y, Walford G, Holmes DR, Jr., Venditti FJ, Berger PB, Jacobs AK,

Stamato NJ, Curtis JP, Sharma $S$ and others. Coronary artery bypass graft surgery versus
drug-eluting stents for patients with isolated proximal left anterior descending disease. J

Am Coll Cardiol 2014;64:2717-26.

8. Hlatky MA, Boothroyd DB. Comparative effectiveness of multivessel coronary artery bypass graft surgery and multivessel percutaneous coronary intervention. Ann Intern Med 2013;159:435.

9. Naik H, White AJ, Chakravarty T, Forrester J, Fontana G, Kar S, Shah PK, Weiss RE, Makkar R. A meta-analysis of 3,773 patients treated with percutaneous coronary intervention or surgery for unprotected left main coronary artery stenosis. JACC Cardiovasc Interv 2009;2:739-47.

10. Park DW, Kim YH, Yun SC, Lee JY, Kim WJ, Kang SJ, Lee SW, Lee CW, Kim JJ, Choo SJ and others. Long-term outcomes after stenting versus coronary artery bypass grafting for unprotected left main coronary artery disease: 10-year results of bare-metal stents and 5 -year results of drug-eluting stents from the ASAN-MAIN (ASAN Medical Center-Left MAIN Revascularization) Registry. J Am Coll Cardiol 2010;56:1366-75.

11. Serruys PW, Morice MC, Kappetein AP, Colombo A, Holmes DR, Mack MJ, Stahle E, Feldman TE, van den Brand $M$, Bass EJ and others. Percutaneous coronary intervention versus coronary-artery bypass grafting for severe coronary artery disease. N Engl J Med 2009;360:961-72.

12. Sipahi I, Akay MH, Dagdelen S, Blitz A, Alhan C. Coronary artery bypass grafting vs percutaneous coronary intervention and long-term mortality and morbidity in 
multivessel disease: meta-analysis of randomized clinical trials of the arterial grafting and stenting era. JAMA Intern Med 2014;174:223-30.

13. Hillis LD, Smith PK, Anderson JL, Bittl JA, Bridges CR, Byrne JG, Cigarroa JE, Disesa VJ, Hiratzka LF, Hutter AM, Jr. and others. 2011 ACCF/AHA Guideline for Coronary Artery Bypass Graft Surgery: executive summary: a report of the American College of Cardiology Foundation/American Heart Association Task Force on Practice Guidelines. Circulation 2011;124:2610-42.

14. Levine GN, Bates ER, Blankenship JC, Bailey SR, Bittl JA, Cercek B, Chambers CE, Ellis SG, Guyton RA, Hollenberg SM and others. 2011 ACCF/AHA/SCAI Guideline for Percutaneous Coronary Intervention: a report of the American College of Cardiology Foundation/American Heart Association Task Force on Practice Guidelines and the Society for Cardiovascular Angiography and Interventions. Circulation 2011;124:e574651.

15. Mohr FW, Morice MC, Kappetein AP, Feldman TE, Stahle E, Colombo A, Mack MJ, Holmes DR, Jr., Morel MA, Van Dyck N and others. Coronary artery bypass graft surgery versus percutaneous coronary intervention in patients with three-vessel disease and left main coronary disease: 5 -year follow-up of the randomised, clinical SYNTAX trial. Lancet 2013;381:629-38.

16. Patel MR, Dehmer GJ, Hirshfeld JW, Smith PK, Spertus JA. ACCF/SCAI/STS/AATS/AHA/ASNC/HFSA/SCCT 2012 Appropriate use criteria for coronary revascularization focused update: a report of the American College of Cardiology

Foundation Appropriate Use Criteria Task Force, Society for Cardiovascular Angiography and Interventions, Society of Thoracic Surgeons, American Association for Thoracic Surgery, American Heart Association, American Society of Nuclear Cardiology, and the Society of Cardiovascular Computed Tomography. J Am Coll Cardiol 2012;59:857-81.

17. McNulty EJ, Ng W, Spertus JA, Zaroff JG, Yeh RW, Ren XM, Lundstrom RJ. Surgical candidacy and selection biases in nonemergent left main stenting: implications for observational studies. JACC Cardiovasc Interv 2011;4:1020-7.

18. Waldo SW, Secemsky EA, O'Brien C, Kennedy KF, Pomerantsev E, Sundt TM, 3rd, McNulty EJ, Scirica BM, Yeh RW. Surgical ineligibility and mortality among patients with unprotected left main or multivessel coronary artery disease undergoing percutaneous coronary intervention. Circulation 2014;130:2295-301.

19. Kline-Rogers E, Share D, Bondie D, Rogers B, Karavite D, Kanten S, Wren P, Bodurka C, Fisk C, McGinnity J and others. Development of a multicenter interventional cardiology database: the Blue Cross Blue Shield of Michigan Cardiovascular Consortium (BMC2) experience. J Interv Cardiol 2002;15:387-92.

20. Moscucci M, Rogers EK, Montoye C, Smith DE, Share D, O'Donnell M, Maxwell-Eward A, Meengs WL, De Franco AC, Patel K and others. Association of a continuous quality improvement initiative with practice and outcome variations of contemporary percutaneous coronary interventions. Circulation 2006;113:814-22.

21. NCDR CathPCI Registry v4.4 Coder's Data Dictionary. https://www.ncdr.com/WebNCDR/docs/public-data-collectiondocuments/cathpci v4 codersdictionary 4-4.pdf?sfvrsn=2. Accessed 28 July, 2015.

22. Gurm HS, Kooiman J, LaLonde T, Grines C, Share D, Seth M. A random forest based risk model for reliable and accurate prediction of receipt of transfusion in patients undergoing percutaneous coronary intervention. PLoS One 2014;9:e96385. 
23. Gurm HS, Seth M, Kooiman J, Share D. A novel tool for reliable and accurate prediction of renal complications in patients undergoing percutaneous coronary intervention. J Am Coll Cardiol 2013;61:2242-8.

24. R Development Core Team. R: A language and environment for statistical computing. Vienna, Austria: R Foundation for Statistical Computing; 2015.

25. Bates D, Maechler M, Bolker B, Walker S. Ime4: Linear mixed-effects models using Eigen and S4. R Package version 1.1-7; 2014.

26. Chan PS, Nichol G, Krumholz HM, Spertus JA, Nallamothu BK, American Heart

Association National Registry of Cardiopulmonary Resuscitation I. Hospital variation in time to defibrillation after in-hospital cardiac arrest. Arch Intern Med 2009;169:1265-73.

27. Panaich SS, Badheka AO, Arora S, Patel NJ, Thakkar B, Patel N, Singh V, Chothani A, Deshmukh A, Agnihotri $K$ and others. Variability in utilization of drug eluting stents in United States: Insights from nationwide inpatient sample. Catheter Cardiovasc Interv 2015.

28. Yeh RW, Rosenfield K, Zelevinsky K, Mauri L, Sakhuja R, Shivapour DM, Lovett A, Weiner $\mathrm{BH}$, Jacobs AK, Normand SL. Sources of hospital variation in short-term readmission rates after percutaneous coronary intervention. Circ Cardiovasc Interv 2012;5:227-36.

29. Share DA, Campbell DA, Birkmeyer N, Prager RL, Gurm HS, Moscucci M, Udow-Phillips $M$, Birkmeyer JD. How a regional collaborative of hospitals and physicians in Michigan cut costs and improved the quality of care. Health Aff (Millwood) 2011;30:636-45.

30. Chu D, Anastacio MM, Mulukutla SR, Lee JS, Smith AJ, Marroquin OC, Sanchez CE, Morell VO, Cook CC, Lico SC and others. Safety and efficacy of implementing a multidisciplinary heart team approach for revascularization in patients with complex coronary artery disease: an observational cohort pilot study. JAMA Surg 2014;149:1109-12.

31. Long J, Luckraz H, Thekkudan J, Maher A, Norell M. Heart team discussion in managing patients with coronary artery disease: outcome and reproducibility. Interact Cardiovasc Thorac Surg 2012;14:594-8.

32. Passeri JJ, Melnitchouk S, Palacios IF, Sundt TM. Continued expansion of the Heart Team concept. Future Cardiol 2015;11:219-28.

33. Al-Haddad MA, Friedlin J, Kesterson J, Waters JA, Aguilar-Saavedra JR, Schmidt CM.

Natural language processing for the development of a clinical registry: a validation study in intraductal papillary mucinous neoplasms. HPB (Oxford) 2010;12:688-95.

34. Murff HJ, FitzHenry F, Matheny ME, Gentry N, Kotter KL, Crimin K, Dittus RS, Rosen AK, Elkin PL, Brown SH and others. Automated identification of postoperative complications within an electronic medical record using natural language processing. JAMA 2011;306:848-55.

35. Wasfy JH, Singal G, O'Brien C, Blumenthal DM, Kennedy KF, Strom JB, Spertus JA, Mauri L, Normand SL, Yeh RW. Enhancing the Prediction of 30-Day Readmission After Percutaneous Coronary Intervention Using Data Extracted by Querying of the Electronic Health Record. Circ Cardiovasc Qual Outcomes 2015;8:477-85.

36. Gasparovic H, Kopjar T, Biocina B. Letter by Gasparovic et al Regarding Article, "Surgical Ineligibility and Mortality Among Patients With Unprotected Left Main or Multivessel Coronary Artery Disease Undergoing Percutaneous Coronary Intervention". Circulation 2015;132:e155.

37. Levey AS, Stevens LA, Schmid CH, Zhang YL, Castro AF, 3rd, Feldman HI, Kusek JW, Eggers $P$, Van Lente $F$, Greene $T$ and others. A new equation to estimate glomerular filtration rate. Ann Intern Med 2009;150:604-12. 


\section{Figure Legends:}

Figure 1: The percentage of percutaneous coronary interventions performed in surgically ineligible patients by hospital - The bar graph represents the percent of PCl cases performed in surgically ineligible patients in each hospital participating in the BMC2 registry. The sites are ordered from the lowest to the highest frequency site.

$\mathrm{PCl}=$ percutaneous coronary intervention

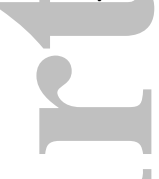

Figure 2: In-hospital outcome rates in all patients - Bar graphs of primary and secondary inhospital outcomes in all patients stratified by ineligibility for surgery. The specific outcome rate is noted above each bar.

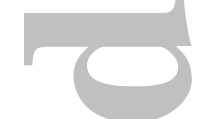

Figure 3: In-hospital outcome rates in the left main PCl subgroup - Bar graphs of primary and secondary in-hospital outcomes in patients who underwent left main PCl stratified by ineligibility for surgery. The specific outcome rate is noted above each bar.

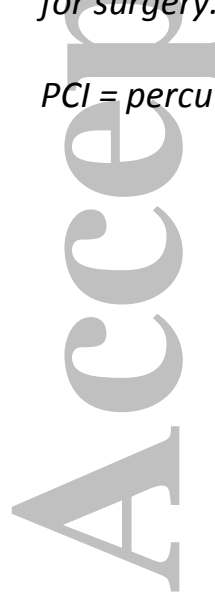




\section{TABLES AND FIGURES}

Table I: Baseline characteristics of surgically ineligible patients and others

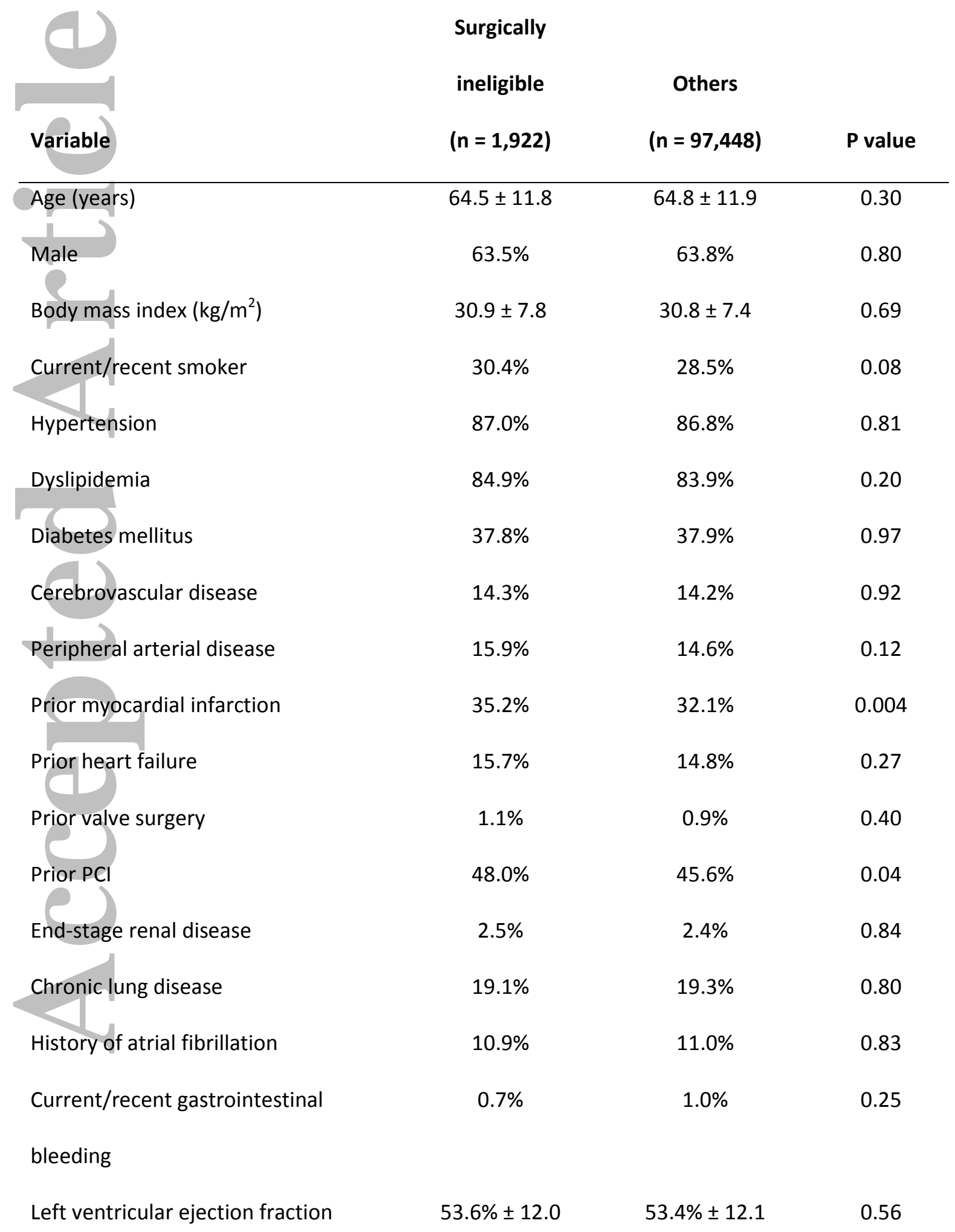




\begin{tabular}{|c|c|c|c|}
\hline Baseline creatinine $(\mathrm{mg} / \mathrm{dL})$ & $1.16 \pm 1.06$ & $1.14 \pm 0.99$ & 0.42 \\
\hline Baseline GFR $\left(\mathrm{ml} / \mathrm{min} / 1.73 \mathrm{~m}^{2}\right)^{*}$ & $74.97 \pm 24.30$ & $75.46 \pm 24.38$ & 0.39 \\
\hline Baseline hemoglobin $(\mathrm{g} / \mathrm{dL})$ & $13.42 \pm 1.80$ & $13.38 \pm 1.86$ & 0.24 \\
\hline Stable angina presentation & $17.1 \%$ & $16.5 \%$ & 0.48 \\
\hline Unstable angina presentation & $49.0 \%$ & $48.3 \%$ & 0.55 \\
\hline NSTEMI presentation & $24.3 \%$ & $25.4 \%$ & 0.28 \\
\hline Cardiogenic shock ${ }^{\dagger}$ & $1.0 \%$ & $0.8 \%$ & 0.20 \\
\hline IABP & $0.7 \%$ & $0.8 \%$ & 0.57 \\
\hline P mechanical ventricular & $0.8 \%$ & $0.6 \%$ & 0.42 \\
\hline Chronic total occlusion treated & $3.5 \%$ & $3.0 \%$ & 0.20 \\
\hline Bifurcation lesion treated & $9.5 \%$ & $9.2 \%$ & 0.63 \\
\hline Pre-procedural predicted mortality & $0.57 \% \pm 2.28$ & $0.59 \% \pm 2.32$ & 0.69 \\
\hline$\geq 1$ "high-risk" PCl-treated lesion** & $55.2 \%$ & $54.6 \%$ & 0.63 \\
\hline Emerge & $2.3 \%$ & $2.1 \%$ & 0.50 \\
\hline \multicolumn{4}{|c|}{ All percentages represent frequencies, except for left ventricular ejection fraction and pre- } \\
\hline \multicolumn{4}{|c|}{ nominal values are used, they are presented as mean \pm standard deviation. } \\
\hline \multicolumn{4}{|c|}{ GFR = glomerular filtration rate; $I A B P=$ intra-aortic balloon pump; NSTEMI = Non ST-elevation } \\
\hline ial infarction; $P C l=$ percutar & coronary inter & & \\
\hline
\end{tabular}


†Represents the frequency of patients in cardiogenic shock within 24 hours prior to the procedure or at the start of the procedure.

$\S$ The pre-procedural risk of mortality was estimated using the BMC2 random forest prediction model available for review at https://bmc2.org/calculators/multi.

**Lesion characteristics consistent with a "C lesion" as defined by the NCDR CathPCI Registry (21).
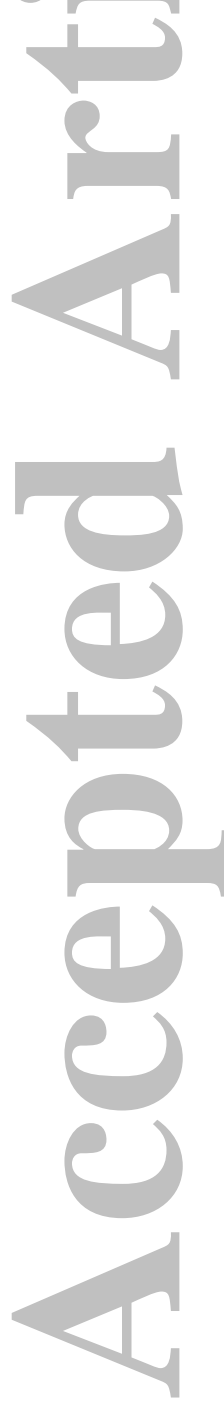

Catheterization and Cardiovascular Interventions

This article is protected by copyright. All rights reserved. 
Table II: Distribution of percutaneously treated coronary artery disease anatomy stratified by surgical ineligibility

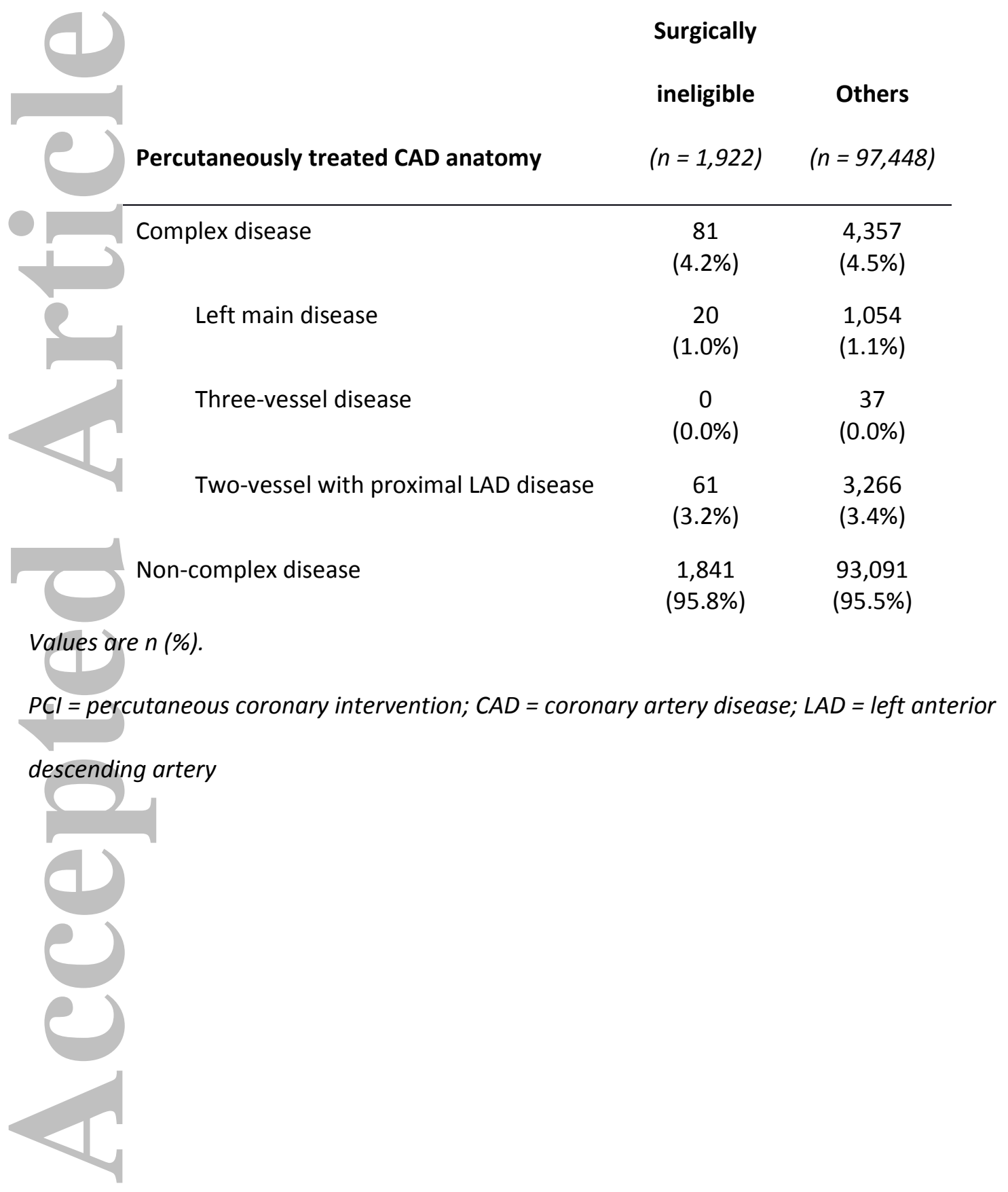


Figure 1:

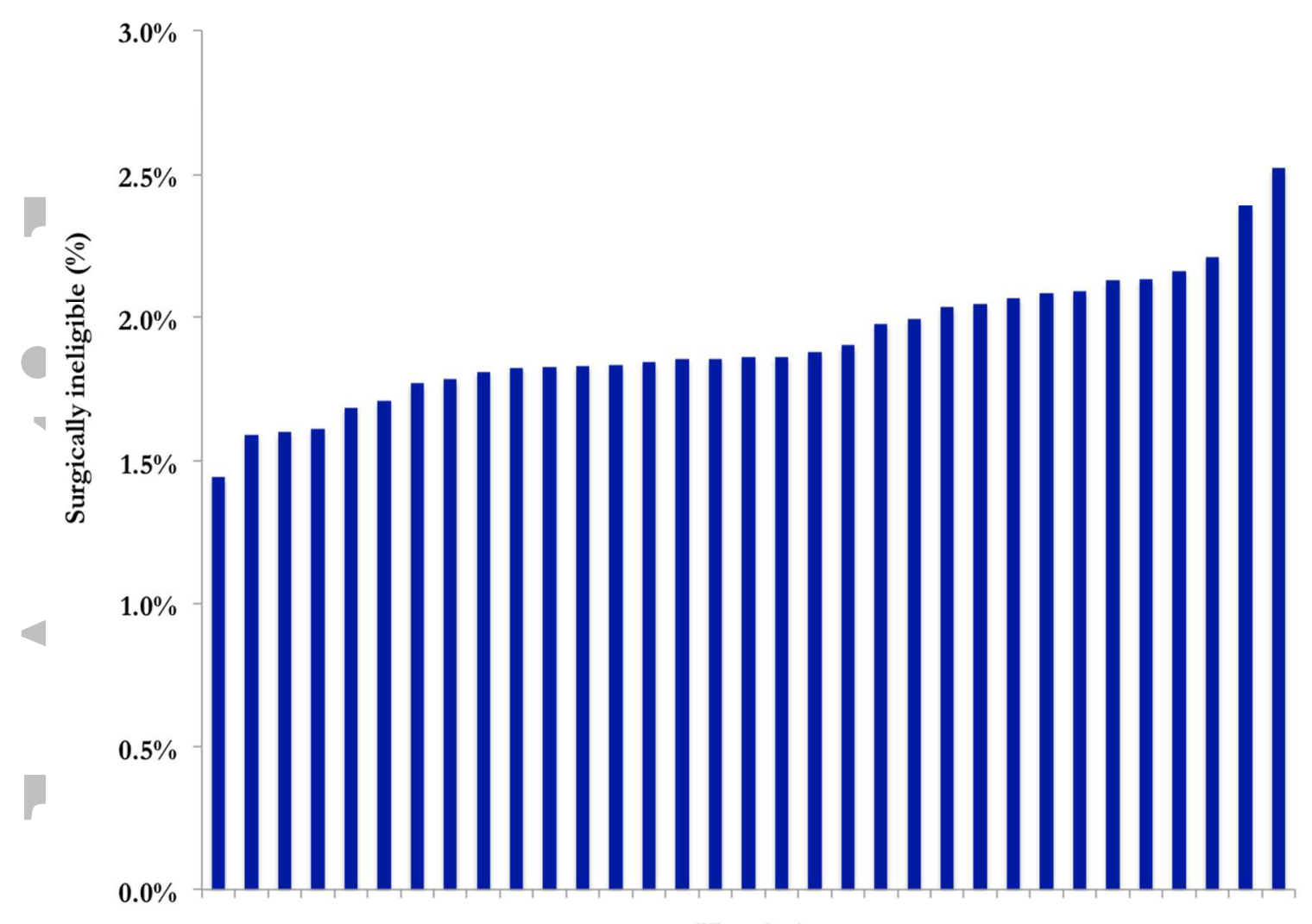

Hospital

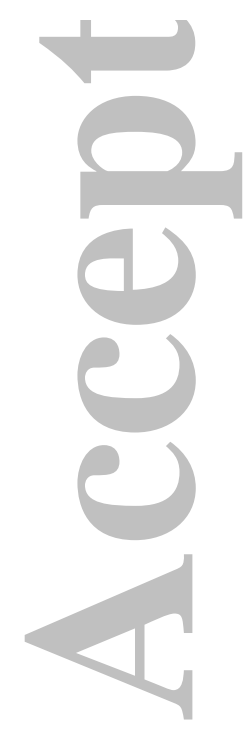




\section{Figure 2:}

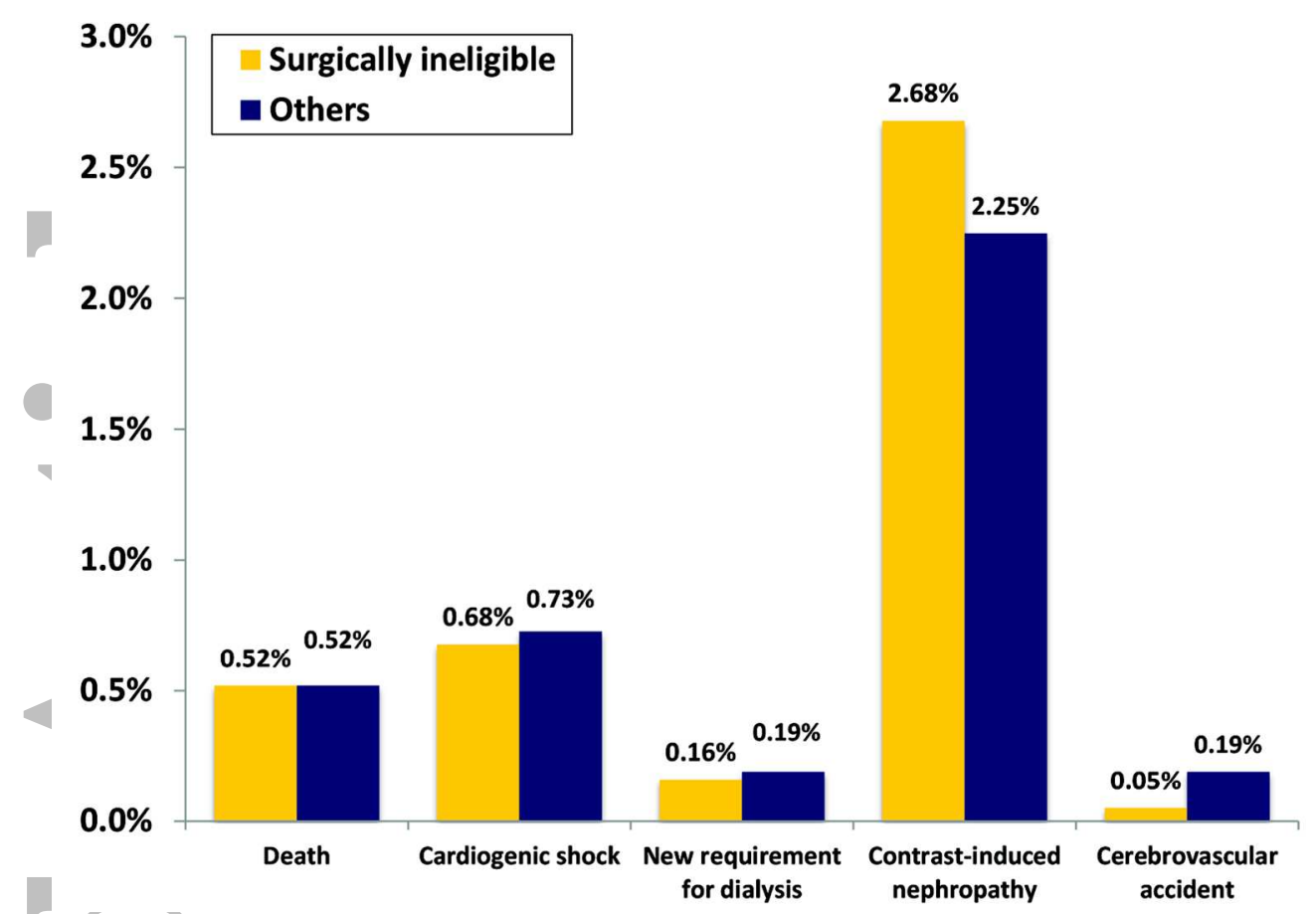




\section{Figure 3:}
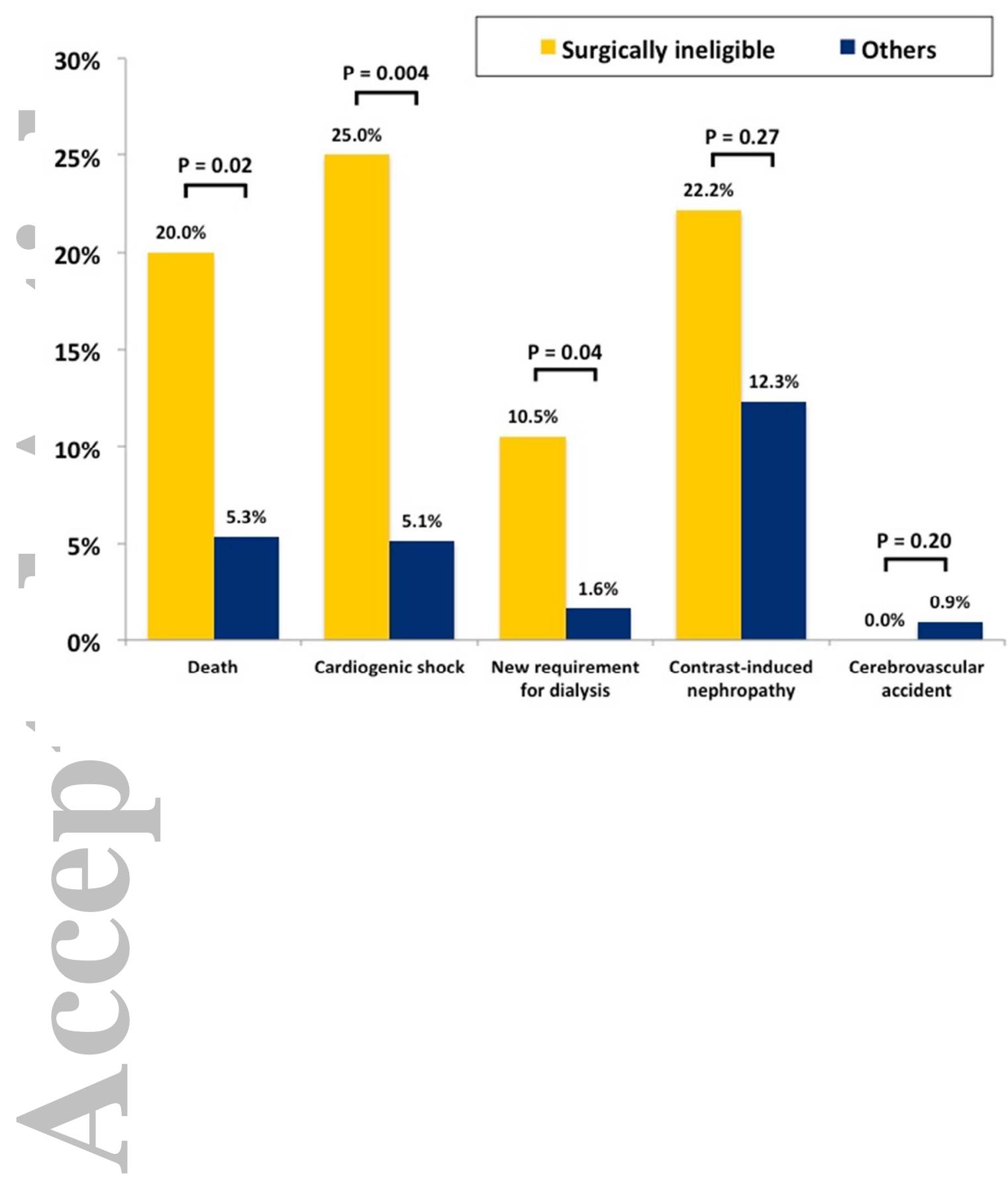
Corresponding Author: Hitinder S. Gurm, MD

Division of Cardiovascular Medicine University of Michigan

2A394, 1500 E. Medical Center Drive, Ann Arbor, MI 48109-5853

734- 232-4276

Fax 734-764-4142

hgurm@med.umich.edu

June 30,16

Steven R. Bailey, MD, FSCAI, FACC

Editor in Chief

Catheterization \& Cardiovascular Interventions

University of Texas Health Science Center, San Antonio, Texas

Re: Clinical Outcomes of Percutaneous Coronary Intervention in Patients Turned Down for Surgical Revascularization

Reference ID: CCI-16-0147.R1

Dear Dr. Bailey,

Thank you for considering our manuscript, "Clinical Outcomes of Percutaneous Coronary Intervention in Patients Turned Down for Surgical Revascularization" for publication in Catheterization \& Cardiovascular Interventions. We appreciate the insightful comments provided by the reviewers, which have enabled us to improve the quality of our manuscript. Enclosed you will find a point-by-point response to each of the comments along with a revised copy of our manuscript.

We confirm that each author has contributed to and approved the final manuscript. We also confirm that this manuscript has not been published or submitted elsewhere. No author has any financial conflict of interest or relationship with industry to disclose. Any possible conflicts have been listed in the manuscript.

Thank you in advance for consideration of our revised manuscript for publication. Please let us know if we may provide you with any further information.

Sincerely,

Hitinder S. Gurm

Devraj Sukul 